九州大学学術情報リポジトリ

Kyushu University Institutional Repository

The Phylogeny of the Genera in the Tribes

Deltocephalini, Paralimnini, and Their Allies (Homoptera, Cicadellidae, Deltocephalinae)

Kamitani, Satoshi

https://doi.org/10.5109/2636

出版情報: ESAKIA. 39，pp.65-108，1999-03-31. Entomological Laboratory， Faculty of Agriculture， Kyushu University

バージョン：

権利関係 : 
ESAKIA, (39): 65-108. March 31, 1999

\title{
The Phylogeny of the Genera in the Tribes Deltocephalini, Paralimnini, and Their Allies (Homoptera, Cicadellidae, Deltocephalinae) *
}

\author{
Satoshi Kamitani \\ Entomological Laboratory, Faculty of Agriculture, \\ Kyushu University, Fukuoka, 812-8581 Japan
}

\begin{abstract}
The phylogenetic relationship among the genera of the subfamily Deltocephalinae and its allies occurring in Japan is studied, and the tribes Deltocephalini and Paralimnini are redefined. The phylogenetic analyses were based upon the maximum-parsimony method by the manual and computer-aided reconstruction with the Fitch characters and Wagner characters (non-weighted or weighted). Sixty-four characters were used for the phylogenetic analyses. Deltocephalini s. str. was concluded to be paraphyletic and includes 2 lineages. The Deltocephalus clade consists of Alobaldia, Deltocephalus, Endria, Recilia, and Paramesodes. Contrary, Futasujinus, Hengchunia, Takagiella, and Yanocephalus belong to the Paralimnus lineage with Paralimnus, Paralaevicephalus, Psammotettix, Metalimnus, Diplocolenus, Jassus, Sorhoanus, Doratura, and Aconurella. The Deltocephalus clade was referred to the tribe Deltocephalini and the Paralimnus clade to the tribe Paralimnini.
\end{abstract}

Key words: phylogeny, morphology, Deltocephalini, Paralimnini, Cicadellidae.

\section{Introduction}

Both tribes of Deltocephalini and Paralimnini comprise small leafhoppers having triangularly produced vertex. These tribes include 137 and 69 genera, respectively, and are widely distributed in the world from the tropical to the semi-polar regions under various environmental conditions. Most of their hosts are monocotyledonous plants including rice and other agricultural crops. Some species of these tribes are well-known serious agricultural pests, such as the zig-zag leafhopper, Recilia dorsalis (Motschulsky), which is the vector of tungro, rice dwarf, rice gall dwarf virus diseases, and the sole vector of the orange leaf MLO disease.

There are many arguments awaiting solution as to their systematics. The 2 tribes are included in Deltocephalinae, which is the largest cicadellid subfamily including more than 700 genera and 10,000 species in 23 tribes. However, the tribes are not rigidly defined and their ranges are variable according to authors.

* Contribution from the Entomological Laboratory, Faculty of Agriculture, Kyushu University, Fukuoka (Ser. 5, No. 22). 
In the early time of leafhopper taxonomy, Deltocephalus, the type genus of Deltocephali, was treated in Jassidae, which was not subdivided into subfamily or tribe (Stål, 1869). Fieber (1869) established a taxonomic group, Deltocephali, including Deltocephalus and Platymetopius. This is a subordinate taxon of the family Jassidae. Deltocephalini is equivalent to a subfamily category in the present sense, and is the oldest available name for Deltocephalinae and Deltocephalini with the principle of coordination. Subsequent authors in the 19 th century began to use the name for higher taxa including Deltocephalus.

Early in the 20th century, there were 2 taxonomic systems related to the classification of Deltocephalini. One is that all leafhoppers similar to Jassus were treated in Jassidae or Jassinae without subdivision into groups. In the other system, Jassinae was subdivided into such groups as Deltocephalusaria and Cicadularia, by Distant (1908).

In the middle of the 20th century, the comparative morphology was introduced to the classification of leafhoppers. Oman (1949) first recognized Deltocephalini in Deltocephalinae with discussion of taxonomic characters, and defined the tribe by the head structures and wing forms (macropterous or semi-macropterous). This tribe comprised many genera of recent Deltocephalinae and Selenocephalinae.

Linnavuori (1960a, b) and Emeljanov (1962) paid special attention to the male genitalia, and modified Oman's definition (1949) of Deltocephalini. Emeljanov (1962) established new tribes: Jassargini (= Paralimnini), Doraturini, and Opsiini in Deltocephalinae, and suggested that Deltocephalini is more closely related to Athysanini than to Jassargini phylogenetically. Recently, most workers follow the higher classification by Linnavuori and Emeljanov. However, Hamilton (1975) suggested the close relation of Deltocephalini to Paralimnini.

An argument about diagnostic characters of Deltocephalini and Paralimnini are as follows. Two sorts of definition in wider sense and strict sense have been applied to Deltocephalini. Deltocephalini in wider sense is based on the 9 taxonomic characters: the contiguity of connective branches at their apices, the shape and markings of vertex, the flattened vertex, the wide genae, the $m 2$-cual cross vein, and the subapical cell of fore wings, the sclerotization of male 10th segment, and the shape of connective (Metcalf, 1927-67; Le Quesne, 1969; Lee and Kwon, 1979; Cheng, 1980).

This definition includes the following problems. Most taxonomic characters are not examined on their polarity, ordering of each state, and distribution in and out-groups. Some characters are present only in a few species of Deltocephalini, and other characters are shared with some other tribes than Deltocephalini. The flatness of vertex is appeared in the tribes other than Deltocephalinae such as Hecalini and Doraturini. The markings of vertex are variable with genera. Therefore, it is difficult to recognize these characters as the synapomorphies of Deltocephalini.

Deltocephalini in strict sense is based on the following 4 characters: the shape of connective, the parallel sided clypellus, the entirely developed carinae of pronotum, and the aedeagal shaft fused to socle (Linnavuori, 1960a, b; Emeljanov, 1962; Nast, 1972; Anufriev and Emeljanov, 1978; Vilbaste, 1982; Ossiannilsson, 1983; Giustina, 1989; Oman et al., 1990).

One of phylogenetic arguments is which tribe or tribes are the sister group of Deltocephalini. Hamilton (1975) placed genera of Deltocephalini and Paralimnini (sensu Oman et al.) in his subtribe Deltocephalina of the subfamily Aphrodinae. He suggested 
that the 2 tribes are closely related to one another. This relationship is also supported by the result of Knight and Webb (1993). Contrary, Emeljanov (1962) suggested that Deltocephalini is related to Athysanini.

The phylogenetic relationship between Deltocephalini and Paralimnini has not yet been discussed. Tribes are often defined on the characters divisible by the large morphological gaps in the traditional taxonomy. However, all taxa must be reflected the phylogenetic relationships and defined by synapomorphy in the phylogenetic systematics.

The present study is aimed to clarify the relationships among the genera of the subfamily Deltocephalinae occurring in Japan, and to redefine the tribes Deltocephalini and Paralimnini phylogenetically. The basic taxonomic system adopted in the present study is relied mainly upon Oman et al. (1990) and partly upon Metcalf (1927-67). The former system is the latest and covered all genera of Deltocephalinae.

I wish to express my sincere gratitude to Prof. J. Yukawa (Ent. Lab., Fac. Agr., Kyushu Univ., Fukuoka) for his directions. My cordial thanks are due to Prof. Emeritus K. Morimoto (Kyushu Univ., Fukuoka) and Assoc. Prof. O. Tadauchi (Ent. Lab., Fac. Agr., Kyushu Univ., Fukuoka) for their helpful comments for the present study. I am indebted to Prof. M. Hayashi (Biol. Lab,, Fac. Educ., Saitama Univ.), who gave me kind suggestions and loaned valuable specimens. I thank Dr. S. Miyamoto (Fukuoka City) and Assoc. Prof. T. Yasunaga (Biol. Lab., Hokkaido Educ. Univ.) for their suggestions.

\section{Specimens examined and methods for observation}

Dried specimens were used in general. The abdomen or entire body was steeped in 5\% $\mathrm{KOH}$ solution, and boiled for 3 to 5 minutes until the organs became soft. After this treatment, the specimens were transferred to $25 \%$ ethanol solution, and dissected and observed under a binocular microscope. The lateral carinae of pronotum was observed through an electric scanning microscope for 16 species: Alobaldia tobae, Recilia oryzae, Exitianus fusconervosus, Laburrus impictifrons, Aconurella orientalis, Hecalus concentralis, Macrosteles quadrimaculatus, Hishimonus sellatus, Yanocephalus yanonis, Psammotettix striatus, Phlogotettix cyclops, Scaphoideus festivus, Doratulina producta, Amimenus mojiensis, Xestocephalus nikkoensis, and Pagaronia okadai.

The specimens examined in this study were loaned from or donated by the following institutions: Entomological Laboratory, Faculty of Agriculture, Kyushu University, Fukuoka, J. Yukawa; Department of Biology, Faculty of Education, Saitama University, Urawa, Saitama, M. Hayashi.

Seven genera of Deltocephalini (sensu Oman, Knight and Nielson) from Japan were examined: Deltocephalus, Alobaldia, Recilia, Futasujinus, Hengchunia, Yanocephalus and Takagiella. Thirty-four genera including the closely related subfamilies were examined for the outgroup comparison. The following 3 species which do not occur in Japan were also used: Deltocephalus pulicaris is the type species of the genus Deltocephalus and the tribe Deltocephalini; Doratura gravis is a species of the type genus of the tribe Doraturini; Endria inimica is a species with several unique features of Deltocephalini.

A List of species examined 
Deltocephalinae, Deltocephalini: Alobaldia tobae (Matsumura) (Figs. 9-16), Hengchunia koshuensis (Matsumura) (Figs. 47-54), Deltocephalus pulicaris (Fallén) (Figs. 17-21), Recilia coronifer (Marshall) (Figs. 64-71), Deltocephalus sp., R. dorsalis (Motschulsky), Endria inimica (Say) (Figs. 30-37), R. oryzae (Matsumura), Futasujinus candidus (Matsumura) (Figs. 38-46), F. towadensis (Matsumura), Takagiella tezuyae (Matsumura) (Figs. 55-63), Yanocephalus yanonis (Matsumura) (Figs. 72-79). Athysanini: Albicostella kiushuensis Vilbaste, Nephotettix cincticeps (Uhler), Exitianus fusconervosus (Motschulsky), Orientus ishidae (Matsumura), Handianus limbifer (Matsumura), Paramesodes albinervosus (Matsumura), Laburrus impictifrons (Boheman), Limotettix striola (Fallen), Matsumurella kogotensis (Matsumura), Scleroracus jakowleffi (Lethierry). Balcluthini: Balclutha incisa (Matsumura). Cicadulini: Elymana sulphurella (Zetterstedt). Doraturini: Aconurella orientalis (Matsumura), Doratura gravis Emeljanov. Hecalini: Hecalus concentralis (Matsumura). Macrostelini: Macrosteles striifrons Anufriev, Yamatotettix flavovittatus Matsumura. Opsiini: Hishimonus sellatus (Uhler). Paralimnini: Diplocolenus evansii (Ashmead) (Figs. 80-87), Paralimnus tamagawanus Matsumura (Figs. 113-121), Jassargus repletus (Fieber) (Figs. 88-95), Psammotettix striatus (Linnaeus) (Figs. 122-130), Metalimnus marmoratus (Flor) (Figs. 96-103), Sorhoanus tritici (Matsumura) (Figs. 131-138), Paralaevicephalus nigrifemoratus (Matsumura) (Figs. 104-112). Platymetopiini: Phlogotetix cyclops (Mulsant et Rey). Scaphoideini: Scaphoideus albovittatus Matsumura, S. festivus Matsumura. Scaphytopiini: Japananus hyalinus (Osborn). Stenometopiini: Doratulina producta (Matsumura), Paivanana indra (Distant). Incertae sedis: Amimenus mojiensis (Matsumura).

Xestocephalinae: Xestocephalus iguchii (Matsumura).

Iassinae: Batracomorphus mundus (Matsumura).

Aphrodinae: Planaphrodes sahlbergi (Signoret).

Selenocephalinae: Drabescus nigrifemoratus (Matsumura).

Paraboloponinae: Parabolopona guttatus (Uhler).

Penthiminae: Penthimia nitida Lethierry.

\section{Characters examined}

The external structure of Deltocephalinae as well as other cicadellid subfamilies has been fairly well studied, and the terms employed are almost coherent. The general terminology in this paper is mainly followed after Blocker et al. (1985) and the venation is after Pope (1994).

The cladistic analysis was based on 64 coded morphological characters, 14 from head, 12 from thoracic, 2 from abdominal, 6 from internal, and 30 from genital structures (Table 1).

Head

1. Shape of Vertex: $(0)$ rounded, less than $1.0 ;(1)$ triangularly produced, 1.0 to 1.4 ; (2) strongly produced, more than 1.4 . The shape of vertex was represented by the relative 
mesal length to the length at side by eye. Knight and Webb (1993, their character 3 ) recognized 2 character states: produced, and similar in length throughout.

2. Head width: (0) narrower; (1) equal; (2) wider. The relative width of the head to pronotum is one of major diagnostic characters in the classification of Deltocephalinae. Knight and Webb (their character 0 ) divided into 2 states: equal or wider, and narrower. In this study, the "equal or wider" state was subdivided.

3. Dorsal surface of vertex: (0) not flattened; (1) weakly flattened; (2) strongly flattened. Hamilton (1975) treated the flatness on the center of vertex as a diagnostic character of the subtribe Doraturina (Aphrodinae, Aphrodini). The vertex was strongly flattened in Doraturini, Hecalini, Aphrodinae, Paraboloponinae, and Penthiminae, but weakly so in some species of Deltocephalinae.

4. Markings of vertex: (0) immaculate or not substandard markings; (1) single transverse band along anterior margin; (2) single or several longitudinal stripes; (3) a row of blackish spots along anterior margin. There were considerable variations in the marking of vertex. Some typical markings such as a black transverse band along its anterior margin of Nephotettix, appeared homoplasically in Deltocephalinae. Knight and Webb (their character 4) recognized 3 kinds of markings: comprising a single pair of spots, other markings and immaculate. In this study, 3 states of typical markings were recognized: single transverse band along the anterior margin of the vertex, single or several longitudinal stripes as seen in Futasujinus or Yamatotettix, and a row of blackish spots along the anterior margin as in Deltocephalus or Recilia.

5. Location of ocellus: (0) located on or posterior to the vertex striae; (1) located on the boundary between face and anterior margin of vertex; (2) located on face. The location of ocellus is important to characterize some cicadellid subfamilies. Ossiannilsson (1983) used this character for a key of Iassinae. One of key characters in Penthiminae is whether or not the ocelli are situated posterior to the striae of the anterior margin of vertex. The ocelli of Aphrodinae, Selenocephalinae, and Paraboloponinae were situated on the striae. This character was used as a phylogenetic character, for the first time, in the present study.

6. Size of ocellus: (0) small; (1) large. The size of ocelli largely varies with genera. The ocelli of Deltocephalus were larger than the head. In contrast, those of Orientus were smaller. Therefore, the 2 states were recognized. This character was applied for the phylogenetic analyses, for the first time, in the present study.

7. Distance between ocellus and eye: (0) distant; (1) close. The distance between the ocellus and the adjacent eye was distinctly shorter in Deltocephalus and its allied genera, whereas it was longer than the diameter of ocellus in most species of Deltocephalinae. Then, this character was used for the analyses as a phylogenetic feature of Deltocephalus group.

8. Lateral frontal suture: (0) directing to outside or middle of ocellus; (1) directing to inside of ocellus; (2) directing medially; (3) short. The lateral frontal sutures extended to ocellus in most Deltocephalinae, but those of the outgroup subfamilies were short or extended medially. Knight and Webb used 2 characters in their study. The relation of the sutures to the ocelli (their character 11) was divided into 2 states: directing towards ocellus, or directing medially. The length (their character 12) was also divided into 2 states: long or short. These characters should be closely related to one another, and combined into a single character. 
9. Transclypeal suture: (0) straight or weakly arched; (1) strongly arched. The shape of clypellus was represented by the transclypeal and clypellal sutures. The shape of the former suture was recognized to have 3 states by Knight and Webb (their character 8): weakly arched, strongly arched, or absent. The state "absent" was unique to Balolina in their study, and not found in the species examined in the present study.

10. Clypellal suture: (0) straight; (1) arched near the apical 1/3. Knight and Webb used the shape of the lateral margin of clypellus for grouping of Balcluthini (their character 9).

11. Incision of gena: (0) not incised; (1) incised; (2) strongly incised. The genal incision below eye has been used as a key character for grouping the tribes of Deltocephalinae. The absence or reduction of incision was observed in Scaphytopiini, and a large incision was present in Hecalini.

12. Width of gena: (0) wide; (1) narrow. Ishihara (1953) used the genal width as a taxonomic character of Deltocephalinae. The genae were narrowed below the lora in Macrostelini and Balcluthini.

13. Shape of genal sensory pit: (0) rounded; (1) elliptical. Cwikla and Freytag (1983) introduced a new character, the genal sensory organ. This consists of the sensory seta and pit. The former was very short and difficult to observe under a binocular microscope. The latter was easily observed under a microscope with $\mathrm{KOH}$ treatment. Although the location was occasionally used for the phylogenetic analyses, the shape was used here for the first time.

14. Location of genal sensory pit: (0) close to lorum; (1) slightly distant from lorum; (2) distant from lorum. The genal sensory pit locates on the gena, but the distance to the lorum or the outer margin of gena is variable. Knight and Webb (their character 13) used the location of genal sensory pit, and divided into 2 states: located on ventrally or dorsally. Their apomorphic state "dorsal" is found only in Argaterma, Sanctahelenia, and Cochlorhinus. This character was based on the distance to the lorum.

\section{Thorax}

15. Lateral carina of pronotum: (0) entirely developed; (1) partly obscure. The lateral carina of pronotum has been used as a taxonomic character of Paralimnini $(=$ Jassargini) by Emeljanov (1962). This carina is difficult to observe in dry material, but becomes clear in $\mathrm{KOH}$-treated specimens under a microscope through the transparent light. Knight and Webb divided into 2 states: carinate or smooth (their character 19), and Kamitani (1997) discussed this character.

16. Longitudinal stripes of pronotum: (0) absent; (1) present. The pronotum of leafhoppers is usually immaculate. The longitudinal stripes are a typical marking, and Knight and Webb used this feature (their character 20).

17. Length of fore wing: (0) macropterous; (1) semi-macropterous; (2) brachypterous. The forms of fore wings were divided into 3 types: the macropterous, brachypterous, and semi-macropterous. Most individuals of Aconurella were brachypterous, but some were macropterous.

18. $\boldsymbol{c}$-scr cross vein of fore wing: (0) absent; (1) present. Sometimes the fore wings have one or more $c$-scr cross veins. The cross veins of Scaphoideus albovittatus were variable with specimens. 
19. $\boldsymbol{m} \mathbf{2}$-cual cross vein of fore wing: (0) absent; (1) present. The $m 2$-cual cross vein divides the inner median cell of fore wings into 2 cells. The apical cell is usually called as the inner subapical cell by Blocker and Triplehorn (1985).

20. Outer subapical cell of fore wing: (0) present; (1) absent. The absence of outer subapical cell on the fore wings is the most important character of Macrostelini and Balcluthini. Knight and Webb regarded this state as a synapomorphy of the 2 tribes (their character 25).

21. Outer subapical cell of fore wing: (0) open; (1) closed. If the outer subapical cell is present, some are closed apically. This character was used as a taxonomic character by Ishihara (1953).

22. Fore wing: width of appendix: (0) wide; (1) distinct; (2) absent or very narrow. The appendix of fore wings was distinct in Deltocephalinae. It was wide in Macrosteles and Balclutha, and narrow in Yanocephalus. This character was used as a phylogenetic character for the first time.

23. Fore wing: termination of appendix: $(0)$ near $\mathrm{CuA} 2$; (1) between $\mathrm{M} 2$ and CuA1; (2) between M1 and M2. The size of appendix depends on its width and length. The length was evaluated by the position of termination.

24. Fore wing: 1st apical cell: (0) not or only acutely abutted; (1) broadly abutted. This character was used by Knight and Webb (their character 24), and divided into 2 states. The abutment between the 1st apical and outer subapical cell was found in some genera of Macrostelini.

25. Hind wing: apical cells: (0) four; (1) three. The R2 and M1 of hind wings fuse in brachypterous Aconurella, and then the apical cells become to be 3 in number. This state was pointed out to be an important character of Doraturini by Emeljanov (1962). Knight and Webb used this character as a phylogenetic feature of Balcluthini, and also divided into 2 states (their character 26).

26. Hind wing: marginal vein: (0) entirely developed; (1) partly disappeared. The marginal vein of hind wings was partly disappeared. This state is an important character of Xestocephalinae (Kamitani 1996).

\section{Abdomen}

27. Female 7th sternum: (0) curved anteriad; (1) almost straight; (2) curved posteriad or undulate. The caudal margin of the 7 th sternum in female varied with species.

28. Male 10th segment: (0) fully sclerotized and long; (1) partly membranous and short; (2) fully membranous. The postgenital segments consist of the 10 th and 11 th segments. Membranization of the 10th segment is variable (Kamitani 1998). Knight and Webb used this character (their character 54) and divided into 2 states: sclerotized at least in part, or membranous. The former state was divided into 2 substates: fully sclerotized and long, and partly membranous and short.

Internal structure

29. Anterior tentorial arm length: (0) longer; (1) nearly equal; (2) shorter; (3) absent. The relative length of the posterior to anterior part of anterior arm was variable and divided into the 4 states. The polarity of this character was the reduction of arms.

30. Dorsal tentorial arm length: (0) shorter; (1) almost equal; (2) longer. The relative length of the basal part of dorsal arm was divided into the 3 states. 
31. Angles between anterior and dorsal arm: (0) less than the right angle; (1) the right angle or over the right angle. The angle between anterior and dorsal arm was less than the right angle in most deltocephaline species.

32. Male apodeme of 1st sternum: (0) small; (1) large. The male apodemes of the 1 st and 2 nd sterna constitute parts of the tymbal organ. Their shapes were various and used as a taxonomic character of Deltocephalinae.

33. Male lateral apodeme of 1st sternum: (0) absent; (1) present. The lateral apodeme of the 1st sternum was developed in Yamatotettix and Macrosteles.

34. Male apodeme of 2 nd sternum: (0) less elongated; (1) elongated; (2) well elongated; (3) well elongated and extending medially. The male apodeme of the 2 nd sternum was more various in the length than that of the 1 st. Some of them exceeded the posterior margin of the 3 rd sternum.

Genital structure

35. Male pygofer: postero-ventral lobe: (0) absent; (1) present. The postero-ventral lobe of the male pygofer is an important key character of Macrostelini. Knight and Webb divided into the 2 states (their character 49).

36. Male pygofer: apical process: (0) absent; (1) present. Some genera of Deltocephalinae had an apical process of the male pygofer. Knight and Webb used it as a phylogenetic character of Paralimnus and Jassargus, and divided into the 2 states (their character 51).

37. Male pygofer: macrosetae: (0) more than 10 macrosetae; (1) less than 10 macrosetae; (2) absent. Two states of this character were recognized by Knight and Webb (their character 52). The intermediate state, provided with less than 10 macrosetae, was used in the present study.

38. Male pygofer: length of lateral lobe: (0) short; (1) nearly equal; (2) long; (3) much longer. The length of the male pygofer lobe was evaluated as a relative length to the mesal sclerotized portion. Four linear states were recognized.

39. Male pygofer: ventral incision: (0) large; (1) small or absent. The male pygofer has a pair of a ventral incisions near connection with the valve. This was distinct in most species, but was small or absent in some species.

40. Male pygofer: short stout setae along posterior margin: (0) absent; (1) present. The short stout setae were absent on the caudal margin of male pygofer lobe in most genera of Deltocephalinae.

41. Male pygofer: inner tooth: (0) absent; (1) present. The inner tooth on male pygofer lobe was used as an important taxonomic character of Xestocephalus (Kamitani 1996).

42. Subgenital valve: relative length to subgenital plate: $(0)$ shorter; (1) equal or greater. The relative length of subgenital valve to the subgenital plate was used as a feature of Paralimnini in the present study, and 2 states were recognized.

43. Subgenital plate: shape: (0) long; (1) short; (2) very short, trapezoid or pentagonal. Two states of this character were recognized by Knight and Webb (their character 57): triangular or trapezoid. Their state "triangular" was subdivided here into 2: long or short. 
44. Subgenital plate: relative length to pygofer: (0) longer; (1) equal; (2) shorter. The relative length of subgenital plate to the caudal margin of pygofer was coded.

45. Subgenital plate: lateral incision: (0) not incised; (1) incised. The lateral incision of subgenital plate occurs in Hengchunia, Takagiella, Diplocolenus, and Jassargus.

46. Subgenital plate: finger-like apical lobe: (0) absent; (1) present. The fingerlike apical lobe of subgenital plate is an important diagnostic character of Macrostelini and Balcluthini. Knight and Webb coded 2 states (their character 58).

47. Subgenital plate: macrosetae seriation: (0) uni-seriated; (1) multi-seriated or irregular; (2) absent. The outer lateral margin of subgenital plate have macrosetae and hair-like setae in most Cicadellidae, but some species have multi-seriated macrosetae on the subgenital plate or have no macrosetae. Knight and Webb divided into only 2 states (their character 60): uni-seriated and multi-seriated. In this study, the state "absent" was added.

48. Subgenital plate: lateral setae: (0) short or absent; (1) long. The subgenital plate has hair-like setae along the outer lateral margin. These setae were easily distinguished from the macrosetae by their diameter. They were sometimes longer than macrosetae.

49. Subgenital plate: apical setae: (0) absent or short; (1) present. The subgenital plate sometimes has a few hair-like setae on its apex. These setae usually present, even when the lateral setae are absent.

50. Style: apophysis: (0) acute; (1) finger-like; (2) robust. Knight and Webb used the apophysis shape of styles in their phylogenetic study (character 61, 62 and 65). Only the character 61 was used in the present study.

51. Style: preapical lobe: (0) strongly produced; (1) present; (2) absent. The shape of preapical lobe was used by Knight and Webb (their character 66), and coded into 4 states: rectangular, triangular, rounded, and digitate. These states were hardly distinguishable. Therefore, this character was divided into the 3 states.

52. Style: length of basal articulating process: (0) short; (1) long. The length of basal articulating process of the style was used as a diagnostic character by Knight and Webb (their character 68).

53. Style: direction of basal articulating process: (0) anteriorly; (1) medially; (2) posteriorly. The direction of basal articulating process of the style was used by Knight and Webb (their character 69).

54. Connective: shape: (0) Y-shaped or U-shaped; (1) racket-shaped; (2) V-shaped or modified V-shaped; (3) linear. In Deltocephalinae, the phylogenetic significance as to the basic shape of connective has been argued by many authors. The typical shapes are Yshaped, linear and racket-shaped. Knight and Webb added a new state, "V-shaped" (their character 69).

55. Connective: length of stem: (0) absent or much shorter; (1) shorter; (2) almost equal; (3) longer. Knight and Webb recognized the length of connective stem as a phylogenetic character (their character 70 ). The length was more variable with the species of Paralimnini.

56. Connective: branch: (0) apart from each other; (1) close to each other, but sometimes apart; (2) fused to each other. This character was closely related to the character 54 , 
"connective shape", but the 2 states "racket-shaped" and "linear" were variable in the contiguity of branches.

57. Connective: relation to aedeagus: (0) articulated; (1) fused to each other. The agglutination of connective with the aedeagus is the most important character of Deltocephalini. Knight and Webb divided into the 3 states (their character 72): articulated, fused, and dissociated. The difference between "fused" and "dissociated" was very small. Therefore, the 2 states were used in the present study.

58. Aedeagus: paraphysis: (0) absent; (1) present. A pair of paraphyses arising from the base of aedeagal shaft or socle were a specific feature of deltocephaline genera. Knight and Webb divided into the 2 states (their character 73).

59. Aedeagus: socle: $(0)$ large; (1) very small or absent. Most leafhoppers have a distinct socle of aedeagus. The reduction of socle appeared polyphyletically.

60. Aedeagus: basal hinge of shaft: (0) absent; (1) present. The basal hinge of aedeagus is present between the shaft and socle, and is the most important key character of Doraturini. Knight and Webb divided into the 2 states (their character 76).

61. Aedeagus: number of shafts: (0) single; (1) paired. Most species have a single shaft of aedeagus. Emeljanov (1962) suggested an apomorphic state "paired" as a taxonomic key character of Opsiini. Knight and Webb recognized the 2 states (their character 75).

62. Aedeagus: apical processes: (0) absent; (1) single; (2) paired; (3) other. The shape of processes arising from the apex of aedeagal shaft was a feature of deltocephaline species.

63. Aedeagus: serrated flange of shaft: (0) absent; (1) present. The serrated flange of aedeagal shaft was an important phylogenetic character to distinguish Nephotettix and Exitianus from Doraturini.

64. Aedeagus: shape: (0) non-linear; (1) linear. The shape of aedeagus is most various and specific among the leafhopper characters, but there is a typical state, "linear", was found in Deltocephalini and Macrostelini.

\section{Phylogenetic reconstruction}

The phylogenetic relationships between species in Deltocephalini and Paralimnini were reconstructed by both manual and computer-aided methods. The former method was based on the shared synapomorphies, and the latter on the maximum-parsimony analyzed by a computer application. The result of observation were summarized in Table 2.

\section{Manual reconstruction}

Generally speaking, an advantage of the manual method is to reflect the intuition and imagination of systematists more directly than the computer-aided method. The relationship reconstructed by the manual method is slightly different from that by the computeraided method, because the former is based on inviolable synapomorphies, or highly weighted characters.

As discussed earlier, the following 13 taxonomic characters were selected for the construction of phylogeny by the manual method: the shape and marking of vertex (character 
1 and 4), the flatness of vertex (character 3), the shape of clypellal suture (character 10), the genal width (character 12), the carina of pronotum (character 15), the $\mathrm{m} 2$-cual cross vein, and subapical cell of fore wings (character 19 and 20), sclerotization of male 10th segment (character 28), the shape of connective (character 54, 56, and 57), and the articulation of aedeagal shaft (character 60). The followings are the distributional pattern of genera in relation to different states of each character.

(1) character 1: Most genera of Deltocephalini, except Yanocephalus with the state 2, had "triangularly produced (state 1)" vertex. However, the state 1 was also shared with other tribes of Deltocephalinae. It is, therefore, difficult to hypothesize this character state as a synapomorphy of Deltocephalini, and must be a synplesiomorphy of Deltocephalinae.

(2) character 3: As to the flatness of vertex (character 3) in Deltocephalini, Alobaldia, Deltocephalus, and Recilia, had the state 0. Endria, Futasujinus, Hengchunia, Takagiella, and Yanocephalus had the state 1 . The state 0 was common in the examined species of Athysanini, Balcluthini, Cicadulini, Macrostelini, Opsiini, and Platymetopiini. In contrast, the state 1 was apomorphic and shared with Paralimnini, Doraturini, and Scaphytopiini. The sharing of the state 1 might be reflected in the phylogenetic relationship to Paralimnini.

(3) character 4: "Several longitudinal stripes (state 2)" and "a row of blackish spots along anterior margin (state 3)" were typical markings of Deltocephalini: Alobaldia, Deltocephalus, and Recilia had the state 3: Futasujinus, Hengchunia and Yanocephalus had the state 2 . These 2 states were more apomorphic than the state 0 , and were found in some other species of Deltocephalinae polyphyletically.

(4) character 10: All species of Deltocephalini, except Takagiella, had the state 0. This state occurred also in many genera of Deltocephalinae, Iassinae, Aphrodinae, and Penthiminae. The rival state 1 was observed in some genera of Deltocephalinae, Xestocephalinae, Selenocephalinae, and Paraboloponinae. The state 0 was plesiomorphic on the basis of outgroup comparison.

(5) character 12: The width of gena below the lorum was wide in all species of Deltocephalini except Hengchunia, but this state was common in Deltocephalinae. Therefore, it should be plesiomorphic.

(6) character 15: Deltocephalini had 2 states as in the character 3: Alobaldia, Deltocephalus, Endria, and Recilia had the state 0: Futasujinus, Hengchunia, Takagiella, and Yanocephalus had the state 1. The apomorphic state 1, which was shared with Paralimnini, Doraturini, and Stenometopiini, might indicate the relationship to Paralimnini and Doraturini.

(7) character 19: Both states occurred in Deltocephalus and Recilia. The state 1 was apomorphic and shared with only some species of Deltocephalini, Paralimnini, and Doraturini.

(8) character 20: All species of Deltocephalini, except Hengchunia with the state 1, had the state 0 . The state 1 was apomorphic and common in Macrostelini and Balcluthini.

(9) character 28: The membranization of male 10th segment was apomorphic in Deltocephalinae. This state was shared with Deltocephalus, Alobaldia, Endria, and Recilia. The other species of this tribe had the state 0 which is plesiomorphic.

(10) character 54: All species of Deltocephalini had apomorphic states: Deltocephalus, Alobaldia, Endria, and Recilia had the state 3: Futasujinus, Hengchunia, and 
Yanocephalus had the state 2: Takagiella had the state 1. These states appeared polyphyletically in some other tribes.

(11) character 56: The contiguity of connective branches was one of the most important characters for Deltocephalini s. lat. This state was shared not only with all species of Deltocephalini but also with Paralimnini and Doraturini. This state supports the Hamilton's system.

(12) character 57: The agglutination of connective with the aedeagus was another most important character for Deltocephalini s. str. This state was apomorphic and shared with some species of Deltocephalini, Yamatotettix, and Paramesodes.

(13) character 60: The articulation of aedeagal shaft and socle was present only in Doraturini, Exitianus, and Nephotettix. The state 0 was plesiomorphic and shared with the remaining species of Deltocephalinae including Deltocephalini.

In the aforementioned 13 characters, some members of Deltocephalini had apomorphic states in 8 characters $(3,4,15,19,28,54,56$, and 57) and synplesiomorphic states in the remaining 5 (character $1,10,12,20$, and 60). In addition to the 8 characters, 7,17 , 52 , and 64,4 characters were newly used for the phylogenetic analysis. These characters were apomorphic states and shared with most genera of Deltocephalini.

The congruence to Deltocephalus, the type genus of Deltocephalini, was evaluated on 10 characters of which states were apomorphic in Deltocephalus: characters 4, 7, 17, 19 , 28, 52, 54, 56, 57, and 64. The congruences of Alobaldia, Endria, and Recilia were high, but those of Futasujinus, Hengchunia, Takagiella, and Yanocephalus were low. The latter 4 genera were more congruent to the species of Paralimnini than Deltocephalus. The congruence of the 4 genera to Paralimnini was evaluated on 8 characters: character 3 , 15, 19, 21, 24, 29, 54, and 56. The Paramesodes placed in Athysanini by Oman et al. had high congruence to Deltocephalus and its genital structure was quite similar to that of the species of Deltocephalini. Therefore, this genus was referred to Deltocephalini.

It is concluded that Deltocephalini in the sense of Oman et al. includes 2 lineages: one consists of Deltocephalus, Alobaldia, Endria, and Recilia: the other of Futasujinus, Hengchunia, Takagiella, and Yanocephalus. The genera of the latter lineage should belong to Paralimnini. Their phylogenetic relationships are shown in Fig. 1. The synapomorphies of Deltocephalini are supported by the following character states: 28-2, 52-1, 54-3, 57-1, and 64-1. In contrast, those of Paralimnini including Futasujinus, Hengchunia, Takagiella, and Yanocephalus are by 3-1, 15-1, 19-1, and 54-1, 2.

\section{Computer-aided reconstructions}

The phylogenetic relationship was reconstructed also by the maximum-parsimony method using morphological characters, although there are several other methods, such as evolutionary-distance, maximum-likelihood, and evolutionary-parsimony (= neighborjointing) methods. Maximum-parsimony, evolutionary-parsimony, and maximum-likelihood methods must assume some evolutionary criteria, and the latter 2 methods require the strict statistic independence between each character (Swofford, 1993). Therefore, for the phylogenetic analysis using morphological characters, which are closely related to each other and have quite low independence between them, the maximum-parsimony is regarded as the best method.

The parsimony for phylogenetic reconstruction is to minimize the tree length, or the amount of evolutionary changes (Swofford, 1993). Trees based on parsimony criteria are 
supported by the greatest number of shared characters and contradicted by the minimum of them, and require the minimum assumptions to explain the distribution of non-congruent characters. The following 4 kinds of characters based on the order and polarity have been used in phylogeny: Wagner, Fitch, Dollo, and Camin and Sokal characters. Wagner character is used to determine the order, hence a character state can shift to a neighbor state by 1 step, but can not shift to further states by 1 step. Fitch character is free from the order and polarity, then each state can change to another state by 1 step. Dollo character is used to determine the order and polarity, and requires that every character state should derived step by step from one ancestral state: the ancestral state can change to a derived state by 1 step, but the derived state can not change to others derived. Camin and Sokal character is irreversible, and is to determine the order and polarity: ancestral states can change to more derived states, but derived states can not change back to less derived or ancestral states. In this study, some multiple state transformation series were recognized as the Wagner character.

There are 2 methods for searching optimal trees: the exact method (exhaustive search and branch-and-bound algorithm) and heuristic method (stepwise addition and branch swapping) (Swofford, 1993). The exact method guarantees to find optimal trees but may require a prohibitive amount of computing time for the medium- to large-sized data sets. The heuristic method does not guarantee optimality but generally require far less computer time. In this study, the heuristic method was employed.

When several most parsimonious trees are obtained by the result of phylogenetic analysis, the resolution is to choose a tree among them, or to compute a consensus tree. Consensus tree is a hierarchical summary of the information which is common in a set of "rival" trees. The consensus tree methods used in this study are of strict and used the 50\% majority-rule. Strict consensus tree contains only those groups appearing in all the rival trees.

Phylogenetic reconstructions were accomplished by 3 performances of the computeraided reconstruction method with the cladistic program PAUP 3.1.1 (Swofford, 1993). The first performance used Fitch characters. The second used Wagner characters. The following 23 characters of multiple states are treated as ordered: the characters $1,2,3,5$, $8,11,14,17,22,23,27,28,29,34,37,38,43,44,51,53,54,55$, and 56. The third used the weighted Wagner characters. The ordered characters are the same as the second performance, and double weights are given to the characters $3,15,19,21,28,54,56$, 57 , and 64 . The results obtained by the heuristic method are sometimes not the same, and then each performance was repeated 10 times in computer.

\section{Analysis using the Fitch characters}

The 50\% majority-rule consensus tree of the 24 most parsimonious trees is shown in Fig. 2. The tree length of the optimal trees was 520 with the consistency index $=0.192$, retention index $=0.501$, rescaled consistency index $=0.096$, and homoplasy index $=$ 0.808. Deltocephalini sensu Oman et al. was polyphyletic in all optimal trees, and 2 lineages were recognized.

The first lineage consisted of 4 genera, Alobaldia, Deltocephalus, Endria, and Recilia, and formed the Deltocephalus clade, which included Paramesodes, Aconurella, Doratura, Metalimnus, and Paralimnus. Paramesodes was referred to Athysanini: Aconurella and Doratura to Doraturini: Metalimnus and Paralimnus to Paralimnini. The consensus fre- 
quency among Deltocephalus, Recilia, and Alobaldia was slightly low, 67\% (Fig. 3). Other consensus frequencies in this clade were $100 \%$. The synapomorphies of this clade included the characters: 18 and 38 .

The second lineage consisted of 4 genera, Futasujinus, Hengchunia, Takagiella, and Yanocephalus. This clade included Sorhoanus, Diplocolenus, Jassargus, Paralaevicephalus, and Psammotettix. The consensus frequency in some nodes of this lineage was $75 \%$ (Fig. 3). Five synapomorphies were common in this lineage: characters $16,24,32,42$, and 43 .

\section{Analysis using the Wagner characters}

The 50\% majority-rule consensus tree of the 60 most parsimonious trees is shown in Fig. 4. The tree length of the optimal trees was 577 with the consistency index $=0.173$, retention index $=0.524$, rescaled consistency index $=0.091$, and homoplasy index $=$ 0.827 . Deltocephalini was polyphyletic, and 2 lineages were recognized. The members of these lineages were the same as those in the previous analysis.

The first lineage included Paramesodes and Yamatotettix. The phylogenetic relationship among Deltocephalus, Recilia, and Alobaldia was polytomy. The consensus frequency is shown in Fig. 5. The characters 28, 53, 54, 57, and 64 were synapomorphic in this lineage.

The second lineage included the following 9 genera: Paralimnus, Metalimnus, Aconurella, Doratura, Sorhoanus, Diplocolenus, Jassargus, Paralaevicephalus, and Psammotettix. All consensus frequencies in this lineage were $100 \%$. Three synapomorphies were common in this lineage: characters 3,15 , and 21 .

The Doratura + Aconurella clade, which was usually placed in Doraturini, was a branch clade included within the Paralimnus clade. Paralimnini sensu Oman et al. must be a paraphyletic group.

\section{Analysis using the weighted Wagner characters}

The 50\% majority-rule consensus tree of the 5 most parsimonious trees is shown in Fig. 6. The tree length of the optimal trees was 630 with the consistency index $=0.181$, retention index $=0.576$, rescaled consistency index $=0.104$, and homoplasy index $=$ 0.819 . Deltocephalini was polyphyletic, and 2 lineages were recognized. The members of these lineages and their synapomorphies were the same as those in the previous analysis. The consensus frequency is shown in Fig. 7.

\section{Discussion on the phylogenetic relationship and systematics}

The results of 4 phylogenetic analyses suggested that Deltocephalini sensu Oman et al. is a paraphyletic group and includes 2 lineages. The first lineage, the Deltocephalus clade, consists of Alobaldia, Deltocephalus, Endria, Recilia, Yamatotettix, and Paramesodes. Futasujinus, Hengchunia, Takagiella, and Yanocephalus belong to the Paralimnus lineage with Paralimnus, Paralaevicephalus, Psammotettix, Metalimnus, Diplocolenus, Sorhoanus, Doratura, and Aconurella. The Deltocephalus clade should be referred to Deltocephalini, and the Paralimnus clade to Paralimnini. Doraturini should be placed in a subclade of Paralimnini, because Doratura and Aconurella constitute a monophyletic group in the Paralimnus clade. 
The Paralimnus clade has a sister relationship with the Deltocephalus clade. The both share 4 synapomorphies: characters $18,19,54$, and 56 . The Deltocephalus clade has 5 synapomorphies: characters $28,53,54,57$, and 64 . The clade Paralimnus has 3 synapomorphies: characters 3,15 , and 21 .

The analyses using non-weighted and weighted Wagner characters suggested that Yamatotettix flavovittatus was related to Deltocephalus sp. In contrast, the Fitch characters suggested that $Y$. flavovittatus was related to Macrosteles striifrons. The latter suggestion was supported by Knight and Webb (1993). They studied all macrosteline genera including this species, and placed it in Macrostelini based on the following synapomorphies: the absence of outer subapical cell on the fore wings and the membranous male 10th segment. In this study, Y. flavovittatus was regarded to be a species of Macrostelini, because the phylogenetic relationships that were constructed by the Fitch characters and by Knight and Webb (1993) seemed to be more reliable than by the non-weighted and weighted Wagner characters. Therefore, the Deltocephalus clade excluding Yamatotettix is referred to Deltocephalini, and includes 5 genera examined. The phylogenetic relationship between them is shown in Fig. 8.

The relationship in the Paralimnus clade is slightly different in the analyses using nonweighted and weighted Wagner characters, but this clade always includes 3 subclades: the Paralimnus, Doratura, and Futasujinus subclade. A taxon combining the Paralimnus and Futasujinus subclade might be paraphyletic, if the Doratura subclade is referred to Doraturini. To recognized a monophyletic taxon, Paralimnini, which is older than Doraturini, therefore, the Paralimnus clade including the Doratura subclade is referred to Paralimnini.

Oman et al. (1990) placed 137 genera in the tribe Deltocephalini and 75 genera in the tribe Paralimnini. All these genera of both tribes and some genera of Athysanini (sensu Oman et al., 1990) were revised here and 62 genera were referred to Deltocephalini. Alaca and Eusceloidia, which were treated as incertae sedis by Oman et al. (1990), have synapomorphies of Deltocephalini, and were included in this tribe.

\section{Definitions of the tribes and enumeration of the included genera Tribe Deltocephalini Fieber, 1869}

Definition: This tribe is defined by the following 5 synapomorphies: the membranous male 10th segment, the style basal articulating process extending medially, the linear connective, the agglutination of connective with the aedeagus, and the linear aedeagus.

Included genera: Alaca, Alobaldia, Alodeltocephalus, Amblysellus, Amplicephalus, Arundanus, Bolarga, Bolivaia, Cabrulus, Cortona, Crumbana, Cruziella, Ctenurella (moved from the Athysanini), Daltonia, Deltanus, Deltazotus, Deltella, Deltocephalus, Destria, Endria, Eusceloidia, Fusanus, Graminella, Haldorus, Horouta, Kanorba, Kansendria, Limpica, Lonatura, Loralia, Lorellana, Loreta, Lusitanocephalus, Maricaona, Mendozellus, Mexara, Neodeltocephalus, Nullamia, Occiplanocephalus, Paramesodes, Parandanus, Peitoullus, Picchuia, Pingellus, Planicephalus, Polyamia, Ragia, Recilia, Reventazonia, Sanctanus, Sanluisia, Saudallygus, Scaphetus, Soractellus, Spathifer, Tideltellus, Toldoanus, Tumupasa, Unerus, Unoka, Vicosa, Wakaya. 


\section{Tribe Paralimnini Distant, 1908}

Definition: This tribe is defined by the following 3 synapomorphies: the weakly flattened vertex, the entirely developed lateral carina of pronotum, and the closed outer subapical cell of fore wings.

Among the following 144 genera, 63 genera with star marks were newly transferred to Paralimnini from Deltocephalini. Pseudosubhimalus, Pseudaraldus, Deltorhynchus, and Neohegir were transferred to Athysanini from Paralimnini.

Included genera: Acharis, Acharista, Aconura, Aconurella, Aconurina, Adarrus, Aflexia*, Agudus*, Alapus*, Altaiotettix, Anareia, Araldus, Ariellus, Arocephalus, Arrailus, Arthaldeus, Artianus, Athysanella, Auridius*, Aurkius, Bampurius, Belaunus*, Boreotettix, Brachydella, Bubulcus*, Calamotettix*, Caloduferna, Canariotettix, Caphodellus*, Cazenus*, Cedarotettix*, Changwhania*, Chelidinus, Chloothea, Cleptochiton*, Coelestinus, Coganus, Condylotes*, Copididonus* Cosmotettix, Cribrus*, Cumbrenanus*, Diplocolenus, Doratura, Doraturopsis, Driotura, Ebarrius*, Elginus*, Enanticephalus, Erdianus, Errastunus, Falcitettix, Flexamia*, Futasujinus*, Futasujinoidella*, Gipru*, Gobicuellus, Goldeus, Hebexa*, Hengchunia*, Hebecephalus*, Henschia, Hiltus, Histipagus, Icaia, Jannius*, Jassargus, Jilinga*, Kaszabinu*, Kazachstanicus*, Ladya*, Laevicephalus* Latalu*, Lebradea, Lecacis*, Lemellus*, Megaulon*, Mendrausus, Mendreus, Metagoldeus, Metalimnus, Miraldu*, Mocuellus, Mocuola, Mogangella, Mongangina, Mongolojassus, Muleyrechia, Myittana, Nanosius*, Naudeus*, Orocastus*, Pantallus, Paragygrus, Paralaevicephalus, Paralimnellus, Paralimnoidella, Paralimnus, Paramesanus, Paramesus, Parapotes, Parargus, Pazu*, Peconus*, Pectinapyga, Pedumella, Philaia, Phlebiastes, Pinumiu*, Platentomus*, Platyacina, Pleargus*, Praganus*, Pratura*, Parunculus*, Pravistylus*, Psammotettix, Pseudolausulus, Pseupalus, Pteropyx, Quartausius, Quaziptus*, Rhoananus, Rosenus, Samuraba*, Savanicus, Sayetus, Secopennis*, Sestrelicola, Sicistella, Sorhoanus, Spartopyge*, Subhimalus*, Takagiella*, Telusus*, Tiaratus, Tigriculus*, Tortotetti*, Turrutus*, Urganus*, Vecaulis*, Vilargus*, Yanocephalus*, Zelenius*.

\section{References}

Anufriev, G. A. \& A. F. Emeljanov, 1978. Les Cicadellides de le Territoire Maritime (Homoptera, Auchenorrhyncha, Cicadellidae). 30: 1-214. (In Russian)

Blocker, H. D. \& B. W. Triplehorn, 1985. External morphology of leafhoppers. In L. R. Nault and L.G. Rodrigues (eds.). The leafhoppers and planthoppers, 41-60. Wiley-Interscience Publication, New York.

Cheng, Y. J., 1980. New leafhopper taxa (Homoptera: Cicadellidae: Deltocephalinae) from Paraguay. J. Kansas ent. Soc., 53: 61-111.

Dallas, W. S., 1970. Rhynchota. Zool. Rec., 6: 472-504.

Distant, W. L., 1906. The Fauna of British India, Including Ceylon and Burma, Rhynchota, vol. 3. 503 pp. Taylor and Francis, London.

Emeljanov, A. F., 1962. New tribes of leafhoppers of the subfamily Euscelinae (Auchenorrhyncha, Cicadellidae). Ent. Oboz. (Moscow), 41: 388-397. (In Russian with English summary) 
Fieber, F. X., 1869. Synopse der europäischen Deltocephali. Verh. zool-bot. Ges. Wien, 19: 201-222.

Giustina, W. della., 1989. Homoptéres Cicadellidae, vol. 3 (compléments), Faune de France 73. 348 pp. Institut National de la Recherche Agronomique, Paris.

Hamilton, K. G. A., 1975. Review of the tribal classification of the leafhopper subfamily Aphrodinae (Deltocephalinae of Authors) of the Holarctic Region (Rhynchota: Homoptera: Cicadellidae). Can. Entomol., 107: 477-498.

Kamitani S., 1992a. Records of leafhoppers and planthoppers collected from tyfton grass. Pulex, (80): 9. (In Japanese)

Kamitani S., 1992b. New distribution and host record of Exitianus nanus from Japan (Homoptera, Cicadellidae, Deltocephalinae). Jpn. J. Ent., 60: 290.

Kamitani S., 1996a. A revision of the genus Xestocephalus Van Duzee (Homoptera, Cicadellidae) of Japan, part 1. Jpn. J. Ent., 64: 602-613.

Kamitani S., 1996b. New records of two deltocephaline leafhoppers (Homoptera, Cicadellidae) from Japan. Jpn. J. Ent., 64: 744.

Knight, W. J. and M. D. Webb, 1993. The phylogenetic relationships between virus vector and other genera of macrosteline leafhoppers, including descriptions of new taxa (Homoptera: Cicadellidae: Deltocephalinae). Syst. Ent., 18: 11-55.

Lee, C. E. \& Y. J. Kwon, 1979. A check list of Auchenorrhyncha from Korea (Homoptera). Illustrated Flora and Fauna of Korea. 23. Insecta 7. 1070 pp. Samhwa Publishing Co., Ltd., Seoul.

Le Quesne, W. J., 1969. Hemiptera (Cicadomorpha, Deltocephalinae). Handbooks for the Identification of British Insects. 2(2b): 65-148. Royal ent. Soc. London, London.

Linnavuori, R. E., 1956a. Leafhopper material from South Spain and Spanish Morocco. Suomen Hyönt. Aikak., 22: 156-165.

Linnavuori, R. E., 1956b. Neotropical Homoptera of the Hungarian National Museum and some other European Museums. Suomen Hyönt. Aikak., 22: 5-35.

Linnavuori, R. E., 1960a. Homoptera: Cicadellidae. Ins. Micronesia, 6: 231-344.

Linnavuori, R. E., 1960b. Cicadellidae (Homoptera, Auchenorrhyncha) of Fiji. Acta ent. Fennica, 15: 1-67.

Linnavuori, R. E. \& D. M. DeLong, 1979. New genera and species of the tribe Deltocephalini from South America (Homoptera: Cicadellidae, Deltocephalinae). Ent. Scand., 10: 43-55.

Maddison, W. P., M. J. Donoghue \& D. R. Maddison, 1984. Outgroup analysis and parsimony. Syst. Zool., 33: 83-103.

Metcalf, Z. P., 1927 -1967. General Catalogue of the Homoptera, Fascicle I-VI. Agri. Res. Service, U.S. Dept. Agr., Washington, D.C.

Nast, J., 1972. Palaearctic Auchenorrhyncha (Homoptera), an Annotated Check List. 550 pp. Polish Scientific Publications, Warszawa.

Oman, P. W., 1949. The Nearctic leafhoppers (Homoptera: Cicadellidae), a generic classification and check list. Mem. ent. Soc. Washington, 3. 253 pp. Ent. Soc. Washington, Washington, D.C.

Oman, P. W., W. J. Knight \& M. W. Nielson, 1990. Leafhoppers (Cicadellidae): A Bibliography, Generic Check List and Index to the World Literature $1956-1985$. 368 pp. C.A.B. International Institute of Entomology, Oxon. 
Oshanin, B., 1908. Verzeichnis der Palaearktischen Hemipteren mit Besonderer Berücksichtigung ihrer Verteilung im Russischenen Reiche, Band II, Homoptera. 492 pp. Buchdruckerei der Kaiserlichen Akademie der Wissenschaften, St. Petersburg.

Ossiannilsson, F., 1983. The Auchenorrhyncha (Homoptera) of Fennoscandia and Denmark, part 3: the family Cicadellidae: Deltocephalinae, catalogue, literature and index, Fauna Entomologica Scandinavica, vol. 7. 979 pp. Scandinavian Science Press Ltd., Copenhagen.

Pope, A., 1994. From functionally four-winged flight to functionally two-winged flight. In A.K. Brodsky (ed.) The Evolution of Insect Flight, 132-151. Oxford Science Publ., Oxford.

Stål, C., 1869. Hemiptera Fabriciana, Fabricianska Hemipterarter, efter de i Köpenhamn och Kiel förvarade typexemplaren granskade och beskrifne, 2. Handl. Svenska Vet. Akad., 8 (1): 1-130.

Swofford, D. L., 1993. PAUP: Phylogenetic Analysis Using Parsimony, version 3.1.1. Computer program distributed by the Illinois National History Survey, Champaign, Illinois.

Vilbaste, J., 1982. Preliminary key for the identification of the nymphs of North European Homoptera Cicadinea, II, Cicadelloidea. Ann. zool. Fennici, 19: 1-20.

Wiley, E. O., 1981. Phylogenetics: the Theory and Practice of Phylogenetic Systematics. xv +439 pp. John Wiley and Sons, New York. 
Table 1. List of characters and character states used in the present study.

\section{Head structure}

1. Vertex, shape: [0] rounded; [1] triangularly produced; [2] strongly produced.

2. Head width: [0] wider; [1] equal; [2] narrower.

3. Vertex, dorsal surface: [0] not flattened; [1] weakly flattened; [2] strongly flattened.

4. Vertex, markings: [0] immaculate or not applicable markings; [1] single transverse band along anterior margin; [2] single or several longitudinal stripes; [3] a row of blackish spots along anterior margin.

5. Ocellus, location: [0] located on or posterior to the vertex striae; [1] located on the boundary between face and anterior margin of vertex; [2] located on face.

6. Ocellus, size: [0] small; [1] large.

7. Ocellus, distance to eye: [0] distant; [1] close.

8. Lateral frontal suture: [0] directing to outside or middle of ocellus; [1] directing to inside of ocellus; [2] directing medially; [3] short.

9. Transclypeal suture: [0] straight or weakly arched; [1] strongly arched.

10. Clypellal suture: [0] straight; [1] arched near the apical 1/3.

11. Gena, incision: [0] not incised; [1] incised; [2] strongly incised.

12. Gena, width: [0] wide; [1] narrow.

13. Genal sensory pit, shape: [0] rounded; [1] elliptical.

14. Genal sensory pit, location: [0] close to lorum; [1] slightly distant from lorum; [2] distant from lorum.

\section{Thoracic character}

15. Pronotum, lateral carinae: [0] entirely developed; [1] partly obscure.

16. Pronotum, longitudinal stripes: [0] absent; [1] present.

17. Fore wing, length: [0] macropterous; [1] semi-macropterous; [2] brachypterous.

18. Fore wing, c-scr cross vein: [0] absent; [1] present.

19. Fore wing, m2-cual cross vein: [0] absent; [1] present.

20. Fore wing, outer subapical cell: [0] present; [1] absent.

21. Fore wing, outer subapical cell, if present: [0] open; [1] close.

22. Fore wing, width of appendix: [0] wide; [1] distinct; [2] absent, or very narrow.

23. Fore wing, termination of appendix: [0] near $\mathrm{CuA} 2$; [1] between $\mathrm{M} 2$ and $\mathrm{CuA}$; [2] between M1 and M2.

24. Fore wing, first apical cell: [0] not or only acutely abutted; [1] broadly abutted.

25. Hind wing, apical cells: [0] four; [1] three.

26. Hind wing, marginal vein: [0] completely developed; [1] partly disappeared.

\section{Abdominal character}

27. Female seventh sternite: [0] curverd anteriad; [1] almost straight; [2] curved posteriad or undulate.

28. Male 10th segment: [0] fully sclerotized and long; [1] partly membranous and short; [2] fully membranous.

\section{Internal structure}

29. Anterior tentorial arm length: [0] longer; [1] nearly equal; [2] shorter; [3] absent.

30. Dorsal tentorial arm length: [0] shorter: [1] almost equal; [2] longer. 
Table 1. (Continued)

31. Angles between anterior and dorsal arm: [0] less than the right angle; [1] the right angle or over the right angle.

32. Male apodeme of first sternum: [0] small; [1] large.

33. Male lateral apodeme of first sternum: [0] absent; [1] present.

34. Male apodeme of second sternum: [0] less elongated; [1] elongated; [2] well elongated; [3] well elongated, and extending medially.

\section{Genital structure}

35. Male pygofer, postero-ventral lobe: [0] absent; [1] present.

36. Male pygofer ,apical process: [0] absent; [1] present.

37. Male pygofer ,macrosetae: [0] more than 10 macrosetae; [1] less than 10 macrosetae; [2] absent.

38. Male pygofer, length of lateral lobe: [0] short; [1] nearly equal; [2] long; [3] much longer.

39. Male pygofer, ventral incision: [0] large; [1] small or absent.

40. Male pygofer, short stout setae along posterior margin: [0] absent; [1] present.

41. Male pygofer, inner tooth: [0] absent; [1] present.

42. Subgenital valve, relative length to subgenital plate: [0] shorter; [1] equal or greater.

43. Subgenital plate, shape: [0] long; [1] short; [2] very short, trapezoid or pentagonal.

44. Subgenital plate, rlative length to pygofer: [0] longer; [1] equal; [2] shorter.

45. Subgenital plate, lateral incision: [0] not incised; [1] incised.

46. Subgenital plate, finger-like apical lobe: [0] absent; [1] present.

47. Subgenital plate, macrosetae seriation: [0] uni-seriated; [1] multi-seriated, or irregular; [2] absent.

48. Subgenital plate, lateral setae: [0] short, or absent; [1] long.

49. Subgenital plate, apical setae: [0] absent or short; [1] present.

50. Style, apophysis: [0] acute; [1] finger-like; [2] robust.

51. Style, preapical lobe: [0] strongly produced; [1] present; [2] absent.

52. Style, length of basal articulating process: [0] short; [1] long.

53. Style, direction of basal articulating process: [0] anterior; [1] medial; [2] posterior.

54. Connective, shape: [0] Y-shaped, U-shaped; [1] racket-shaped; [2] V-shaped, modified V-shaped; [3] linear.

55. Connective, length of stem: [0] absent, or much shorter; [1] shorter; [2] almost equal; [3] longer.

56. Connective, branch: [0] apart from each other; [1] close to each other, but sometimes apart; [2] fused to each other.

57. Connective, relation to aedeagus: [0] articulated; [1] fused to each other.

58. Aedeagus, paraphysis: [0] absent; [1] present.

59. Aedeagus, socle: [0] large; [1] very small or absent.

60. Aedeagus, basal hinge of shaft: [0] absent; [1] present.

61. Aedeagus, number of shafts: [0] single; [1] paired.

62. Aedeagus, apical processes: [0] absent; [1] single; [2] paired; [3] other.

63. Aedeagus, serrated flange of shaft: [0] absent; [1] present.

64. Aedeagus, shape: [0] non-linear; [1] linear. 
Table 2. Data matrix used for phylogenetic analyses of Deltocephalini

\begin{tabular}{|c|c|c|c|c|c|c|c|c|c|c|c|c|c|c|c|c|c|c|c|c|c|c|c|c|c|c|c|c|c|c|c|c|}
\hline & 1 & 2 & 3 & 4 & 5 & 6 & 7 & 8 & 9 & 101 & 11 & 12 & 13 & 14. & 15 & 16 & 171 & 181 & 192 & 202 & $21 \quad 2$ & 22 & 23 & 24 & 25 & 262 & & & 29 & & & 32 \\
\hline Alobaldia tobae & 1 & 1 & 0 & 3 & 1 & 1 & 1 & 0 & 0 & 0 & 1 & 0 & 1 & 1 & 0 & 0 & 0 & 0 & 0 & $0 \quad 0$ & 0 & 1 & 1 & 0 & 0 & 0 & 1 & 2 & 1 & 0 & 1 & 1 \\
\hline Deltocephalus pulicarius & 1 & 1 & 0 & 3 & 1 & 1 & 0 & 0 & 0 & 0 & 1 & 0 & 1 & 1 & 0 & 0 & 1 & 0 & 1 & 0 & 0 & 1 & 1 & 0 & $?$ & 0 & & & ? & $?$ & $?$ & $?$ \\
\hline Deltocephalus so. & 1 & 1 & 0 & 3 & 1 & 1 & 1 & 0 & 0 & 0 & 1 & 0 & 1 & 1 & 0 & 0 & 1 & 0 & 00 & 0 & 0 & & 1 & 1 & 0 & 0 & & & 0 & 0 & 0 & 0 \\
\hline Endria inimica & 1 & 1 & 1 & 0 & 1 & 1 & 1 & 0 & 0 & 0 & 1 & 0 & 1 & 1 & 0 & 0 & 1 & 11 & 10 & 00 & 0 & 1 & 1 & 0 & 0 & 0 & 0 & 2 & 0 & 0 & 0 & 1 \\
\hline Futasujmus candidus & 1 & 2 & 1 & 2 & 1 & 1 & 0 & 0 & 0 & 0 & 1 & 0 & 1 & 0 & 1 & 1 & 1 & 0 & 10 & 0 & 1 & & 1 & 1 & 0 & 0 & & & & 0 & & 0 \\
\hline Futasujinus towadensis & 1 & 2 & 1 & 2 & 1 & 1 & 0 & 0 & 0 & 0 & 1 & 0 & 1 & 0 & 1 & 1 & 1 & 0 & 10 & & & & 1 & 1 & 0 & 0 & & & & 0 & & 0 \\
\hline Hengchunia koshuensis & 1 & 1 & 1 & 2 & 1 & 0 & 0 & 0 & 0 & 0 & 1 & 1 & 1 & 1 & 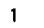 & 1 & 0 & 0 & 1 & 1 & ? & 1 & 1 & 0 & 0 & 0 & 0 & 0 & 0 & 0 & 0 & 1 \\
\hline Recilia coronifer & 1 & 1 & 0 & 3 & 1 & 1 & 1 & 0 & 0 & 0 & 1 & 0 & $i$ & $i$ & 0 & 0 & 0 & 0 & 00 & 00 & 0 & 1 & 1 & 0 & 0 & 0 & 1 & 2 & 1 & 0 & 0 & 1 \\
\hline cilia oryzae & 1 & 1 & 0 & 3 & 1 & 1 & 1 & 0 & 0 & 0 & 1 & 0 & 1 & 1 & 0 & 0 & 0 & 0 & 00 & 00 & 0 & & 1 & 0 & 0 & 0 & & & & 0 & 0 & 1 \\
\hline Recilia dorsalis & 1 & 1 & 0 & 3 & 1 & 1 & 1 & 0 & 0 & $0 / 1$ & 1 & 0 & 1 & 1 & 0 & 0 & 0 & 1 & 10 & 0 & 0 & 1 & 1 & 0 & 0 & 0 & 1 & & 1 & 0 & 0 & 1 \\
\hline Takagiella tezuyae & 1 & 1 & 1 & 0 & 1 & 1 & 1 & 0 & 0 & 1 & 1 & 0 & 1 & 1 & 1 &  & 0 & 0 & 1 & 0 & 1 & 1 & 1 & 1 & 0 & 0 & 2 & 0 & 0 & 0 & 0 & 0 \\
\hline Yanoce & 2 & 2 & 1 & 2 & 1 & 0 & 0 & 0 & 0 & 0 & 1 & 0 & 1 & 1 & 1 & 1 & 1 & 0 & 10 & 0 & & & 0 & & & & & & & & & 0 \\
\hline Albicostella kiushuensis & 2 & 0 & 0 & 0 & 1 & 1 & $\overline{0}$ & 0 & 0 & 0 & 1 & 0 & 1 & 0 & 0 & 0 & 0 & 00 & 00 & 00 & 0 & 1 & 1 & 0 & 0 & 0 & & 0 & 0 & 0 & 0 & \\
\hline Exitianus fusconervosus & $i$ & 2 & 0 & 1 & 1 & 1 & 0 & 0 & 0 & 0 & 1 & 1 & 1 & 0 & 0 & 0 & 0 & 00 & 00 & 0 & 0 & 0 & 2 & 0 & 0 & 0 & 0 & 1 & 0 & 0 & & 1 \\
\hline Hann & 1 & 2 & 0 & 1 & 1 & 0 & 0 & 0 & 0 & 0 & $i$ & 1 & 1 & 1 & 0 & 0 & 1 & 00 & 00 & 00 & & & & & 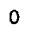 & 0 & 0 & 0 & 0 & & & 1 \\
\hline Laburrus impictifrons & 1 & 2 & 0 & 0 & 1 & 0 & 0 & 0 & 1 & 1 & 1 & 0 & 0 & $i$ & 0 & 0 & 1 & 00 & 00 & 00 & & & 1 & 0 & 0 & 0 & & & & & 1 & 1 \\
\hline Limotettix striola & 0 & 2 & 0 & 1 & 1 & 1 & 0 & 0 & 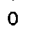 & 0 & 1 & 0 & 1 & 1 & 0 & 0 & 0 & 0 & 00 & 00 & & 0 & 1 & 0 & 0 & 0 & 2 & & 2 & 0 & 0 & 1 \\
\hline Matsumurella kogotensis & 1 & $i$ & 0 & 0 & $i$ & $i$ & 0 & 0 & 0 & 1 & 1 & 0 & 1 & 0 & 0 & 0 & 0 & 0 & 1 & 0 & & 1 & 1 & 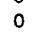 & 0 & 0 & 0 & 0 & 0 & 0 & & 0 \\
\hline 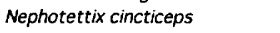 & 1 & 0 & 0 & 1 & 1 & 1 & 0 & 0 & 0 & 0 & 1 & 1 & 1 & 0 & 0 & 0 & 0 & 0 & 00 & 0 & 1 & & 2 & 0 & 0 & 0 & & & & 0 & & 1 \\
\hline Orientus ishidae & 1 & 0 & 0 & 0 & 1 & 0 & 0 & 0 & 0 & 1 & 1 & 1 & 1 & 0 & 0 & 0 & 0 & 0 & 00 & 0 & 0 & 1 & 1 & 0 & 0 & & & & & 0 & 1 & 0 \\
\hline Paramesodes albinervosus & 1 & 2 & 0 & 1 & 1 & 1 & 0 & 0 & 0 & 0 & 1 & 0 & 1 & $1 / 2$ & 0 & 0 & 0 & 1 & 1 & 0 & 0 & 1 & 1 & 0 & 0 & 0 & 0 & & 2 & 0 & 0 & 0 \\
\hline Sclero & 1 & 1 & 0 & 0 & 1 & 1 & & 0 & 0 & 0 & & 0 & 1 & & 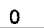 & & 0 & 0 & & $0 / 1$ & & & 2 & 0 & . & 0 & 1 & 1 & & 0 & 0 & 1 \\
\hline Balclutha incisa & 0 & 0 & 0 & 0 & 1 & 1 & 1 & 1 & & 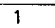 & 1 & 1 & 1 & 0 & 0 & 0 & 0 & 0 & 0 & $1 ?$ & $?$ & 1 & 2 & 0 & 1 & 0 & 0 & 1 & 2 & 0 & 1 & 0 \\
\hline Elymana sulphurella & 2 & 1 & 0 & 0 & 1 & 0 & 0 & 0 & 0 & 0 & 1 & 1 & 0 & 0 & 0 & 0 & 0 & $0 \quad$ & 0 & 00 & 0 & 1 & 1 & 0 & 0 & 0 & 2 & 0 & 0 & 0 & 0 & 1 \\
\hline Aconurella orientalis & 1 & 2 & 1 & 3 & 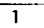 & 0 & & & 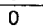 & 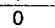 & 1 & 0 & 1 & 0 & 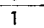 & & $0 / 2$ & 1 & & $0 / 1 ?$ & & & 1 & 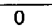 & 1 & 0 & 0 & 0 & & 0 & & 1 \\
\hline & 1 & 1 & & & 1 & 0 & 0 & & & 0 & 1 & & & & & 0 & 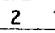 & $\therefore$ & 2 & & & & & & & & & & & & & \\
\hline Hecalus concentralis & 2 & 0 & 2 & 0 & 1 & 0 & 1 & 2 & 0 & 0 & $-\frac{1}{2}$ & 0 & 0 & 0 & 0 & 0 & 1 & 0 & 0 & 0 & 0 & 1 & 2 & 0 & 0 & 0 & 0 & 1 & 0 & 0 & 1 & 1 \\
\hline Macrosteles striifrons & 1 & 1 & 0 & 0 & 1 & 1 & 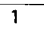 & 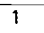 & 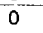 & 0 & 1 & 1 & 1 & 0 & 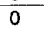 & 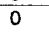 & 0 & 0 & 0.1 & 1 & 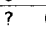 & 0 & 1 & 0 & 0 & 0 & 0 & 2 & & 0 & 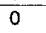 & 0 \\
\hline tatus & 1 & & 0 & & & 1 & 1 & & 0 & 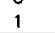 & & 1 & & & & & 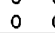 & & & & & & & 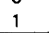 & & & & 2 & & & & 0 \\
\hline Hishimonus sellatu & 2 & 0 & 0 & 0 & 1 & 1 & 1 & 1 & 0 & 1 & 1 & 1 & 0 & 0 & 0 & 0 & 0 & 0 & & & & & & & & & 2 & 1 & & & & \\
\hline Diplocolenus evansii & 1 & 2 & 1 & 0 & 1 & 0 & 0 & V & 0 & 0 & 1 & $-\frac{1}{0}$ & 0 & 0 & 1 & 0 & 1 & 0 & 1 & $u$ & 0 & 2 & 1 & 0 & 0 & 0 & 0 & 0 & 1 & 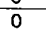 & & \\
\hline Jas. & 1 & 2 & 1 & 3 & & & & 0 & 0 & 0 & & & & & & & 1 & & & & & & & & & & & & & & & 0 \\
\hline Metali & 1 & 1 & 1 & 2 & 1 & 1 & 0 & 0 & 0 & 0 & 1 & 0 & 0 & 1 & 1 & 1 & . & 1 &  & & & & 1 & 1 & 0 & 0 & 0 & 0 & 2 & 0 & & 1 \\
\hline Paralaevicephalus nigrifemoratu & 1 & 1 & $i$ & 0 & 1 & 1 & 0 & 0 & 0 & 0 & 1 & 0 & 1 & 1 & 1 & 1 & 1 & 0 & 1 & 0 & & 1 & 1 & 1 & 0 & 0 & 0 & 0 & 2 & & 0 & 0 \\
\hline Paralimnus tamaga & 1 & 1 & 1 & 1 & & 1 & & 0 & 0 & 1 & 1 & 0 & 1 & & 1 & 0 & 0 &  & 10 & & & & 1 & 0 & 0 & & & & & & & 1 \\
\hline striatus & 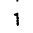 & 2 & 1 & & & &  & 0 &  & 0 & 1 & 0 & 1 & & & 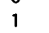 & 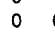 & 0 & & & & & & . & & & & & & & & 0 \\
\hline Sorhoanus tritic & 1 & 2 & 1 & 0 & 1 & 0 & 0 & 0 & 0 & 0 & & & 1 & 1 & 1 & & & & 1 & & & & . & 1 & 0 & 0 & 2 & 0 & & & & \\
\hline Phlogotettix cyclop & 1 & 1 & 0 & 0 & 1 & 1 & 1 & 0 & 0 & 1 & 1 & $\frac{5}{1}$ & 0 & $\frac{1}{1}$ & 0 & 0 & 0 & 0 & c & 0 & & 1 & 1 & 0 & 0 & 0 & 0 & 0 & & 0 & 0 & 0 \\
\hline & 1 & 0 & 0 & 2 & & & & & & $i$ & 1 & 0 & 1 & & & 1 & 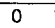 & 1 & & & & & & & & & & & & & & 1 \\
\hline Scaphoideus festivus & 1 & 0 & 1 & 1 & 1 & 1 & 1 & 0 & 0 & 1 & 1 & 1 & $i$ & 1 & 0 & 0 & 0 & U & 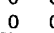 & & & & 2 & 0 & 0 & 0 & 0 & 0 & & $?$ & & 1 \\
\hline Japananus hyalinu &  & 0 & 1 & 3 & 1 & c & 1 & 0 & 0 & 1 & 0 & 0 & 1 & 0 & 0 & 0 & 0 & 0 & 0 & 0 & 0 & 1 & 2 & & & & 0 & 0 & 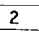 & & & \\
\hline Dor & l & 0 & 1 & 0 & 1 & 0 & 0 & 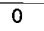 & 0 & 1 & 1 & 1 & 1 & 0 & 1 & 0 & 1 & 1 & 0 & 0 & & 1 & 1 & 0 & 0 & 0 & 2 & 0 & 0 & 1 & 0 & \\
\hline a indra & ; & 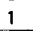 & ; & 0 & i & 0 & 1 & 0 & 0 & 0 & 1 & 1 & $i$ & & & 0 & 1 & 0 & 0 & & & & & 0 &  & 0 & 2 & 1 & 0 & 0 & 0 & 0 \\
\hline$\overline{A m}$ & 1 & 0 & 0 & 0 & 1 & 0 & 1 & 0 & 0 & 1 & 1 & 1 & 0 & & 0 & 0 & 0 & 0 & & & & & 1 & & & 0 & 0 & 0 & 0 & & & \\
\hline & 2 & 0 & 0 & 0 & 1 & 1 & 0 & $\frac{5}{2}$ & 0 & 1 & 1 & 0 & 0 & $?$ & 0 & 0 & 0 & 0 & 1 & 0 & 0 & 1 & 1 & 0 & 0 & 1 & 1 & 1 & 3 & 0 & 1 & 1 \\
\hline Batracon & 1 & 0 & 0 & 0 & 2 & 1 & 0 & 3 & 0 & 0 & 1 & 0 & 0 & 1 & 0 & 0 & 0 & 0 & & 0 & & 1 & & 0 & 1 & 1 & 1 & 1 & 3 & 0 & $?$ & 0 \\
\hline Planaphrodes sahlbergi & 2 & 1 & 2 & 0 & 0 & 1 & 0 & 2 & 0 & 0 & 1 & 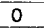 & 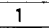 & - & 0 & 0 & 1 & 0 & & & & & 0 & 0 & 0 & 0 & 2 & 1 & 3 & & & \\
\hline & 0 & 1 & 0 & 0 & 0 & 0 & 0 & & 0 & & & & & & & & & & & & & & & & & & & & & & & \\
\hline Parab & 1 & 1 & 2 & 0 & 0 & 0 & 0 & 2 & 0 & 1 & 1 & 0 & 0 & 0 & 0 & 0 & 0 & 0 & 0 & 0 & 0 & 1 & 1 & 0 & 0 & 0 & 1 & 1 & 3 & 2 & 1 & 0 \\
\hline Penthimia nitida & 1 & 0 & 2 & 0 & 0 & 0 & 0 & 3 & 0 & 0 & 1 & 1 & 0 & $?$ & 0 & 0 & 0 & 1 & 1 & & & & & 0 & 0 & & & & & & & \\
\hline
\end{tabular}


Table 2. (Continued)

\begin{tabular}{|c|c|c|c|c|c|c|c|c|c|c|c|c|c|c|c|c|c|c|c|c|c|c|c|c|c|c|c|c|c|c|c|c|}
\hline & 33 & 34 & 35 & 36 & 37 & 38 & 39 & 40 & 41 & 42 & 43 & 44 & 45 & 46 & 47 & 48 & 49 & 50 & 51 & & 53 & 54 & & 56 & 57 & 585 & 596 & $60-6$ & & 626 & $5 \longdiv { 6 4 }$ & \\
\hline Alobaldia tobae & 0 & 2 & 0 & 0 & 0 & 2 & 0 & 1 & 0 & 0 & 0 & 1 & 0 & 0 & 0 & 1 & 1 & 0 & 0 & 1 & 1 & 3 & 1 & 2 & 1 & 1 & 1 & 0 & 0 & 00 & $\begin{array}{ll}0 & 1\end{array}$ & \\
\hline Deltocephalus pulicarius & & $?$ & 0 & 3 & ? & $?$ & $?$ & ? & $?$ & 0 & $?$ & $?$ & 0 & $?$ & $?$ & $?$ & $?$ & $?$ & $?$ & $?$ & $?$ & ? & ? & ? & $?$ & 0 & & & & & 0 & \\
\hline Deltocephalus $s p$. & 0 & 3 & 0 & 0 & 0 & 1 & 0 & 1 & 0 & 0 & 0 & 1 & 0 & 0 & 0 & 0 & 1 & 0 & 1 & 1 & 1 & 3 & 1 & 2 & & 0 & 0 & & & & & \\
\hline Endria inimica & 0 & 1 & 0 & 0 & 0 & 1 & 0 & 1 & 0 & 0 & 0 & 0 & 0 & 0 & 0 & 0 & 0 & 1 & 1 & 1 & 2 & 3 & 0 & 2 & 1 & 0 & 1 & 0 & 0 & 0 & 0 & \\
\hline Futasujinus candidus & 0 & 1 & 0 & 1 & 0 & 2 & 1 & 0 & 0 & 1 & 1 & 0 & 0 & 0 & 0 & 0 & 0 & 1 & 1 & 0 & 0 & 2 & 0 & 2 & 0 & 0 & 1 & 0 & & & & \\
\hline Futasujinus towadensis & 0 & 1 & 0 & 1 & 0 & 2 & 1 & 0 & 0 & 1 & 1 & 0 & 0 & 0 & 0 & 1 & & & 1 & 0 & & & & & & & & & & & & \\
\hline Hengchunia koshuensis & 0 & 1 & 0 & 1 & 0 & 1 & 1 & 0 & 0 & 1 & 2 & 2 & 1 & 0 & 0 & 0 & 0 & 2 & 0 & 0 & 0 & 2 & 0 & 1 & & 1 & 1 & 0 & & 2 & 0 & \\
\hline Recilia coronifer & 0 & 2 & 0 & 0 & 0 & 2 & 0 & 1 & 0 & 0 & 2 & 2 & 0 & 0 & 0 & 0 & 0 & 1 & 1 & 1 & 0 & 3 & 1 & 2 & 1 & 0 & 1 & 0 & 0 & 1 & 1 & \\
\hline Recilia oryzae & 0 & 3 & 0 & 0 & 0 & 2 & 0 & 1 & 0 & 0 & 1 & 2 & 0 & 0 & 0 & 0 & 1 & 0 & 1 & 1 & 1 & 3 & & & & 0 & & & & & & \\
\hline Recilia dorsalis & 0 & 3 & 0 & 0 & 0 & 1 & 0 & 1 & 0 & 0 & 0 & 1 & 0 & 0 & 0 & 1 & $i$ & & 0 & 1 & & & & & & 0 & & 0 & & 0 & 0 & \\
\hline Takagiella tezuyae & 0 & 1 & 0 & 0 & 0 & 1 & 0 & 0 & 0 & 1 & 2 & 2 & 1 & 0 & 0 & 0 & 1 & 2 & 1 & 0 & 1 & 1 & 1 & 2 & 0 & 0 & 0 & 0 & 0 & 0 & 0 & \\
\hline Yanocephalus yanonis & 0 & 1 & 0 & 0 & 0 & 0 & 1 & 0 & 0 & 1 & 2 & 0 & 0 & $\underline{0}$ & 0 & 0 & $\underline{0}$ & 1 & 1 & 0 & 0 & 2 & & & & 0 & 0 & & & & & \\
\hline Albicostella kiushuensis & 0 & 0 & 0 & 1 & 1 & 3 & 1 & 0 & 0 & 0 & 2 & 0 & 0 & $\overline{0}$ & 1 & 0 & $\overline{0}$ & & 2 & 0 & & & & & & 0 & 0 & & & & 0 & \\
\hline Exitianus & 0 & 1 & 0 & 0 & 1 & 3 & 1 & 0 & 0 & 1 & 0 & 0 & 0 & 0 & 0 & 0 & 0 & 0 & 1 & 0 & 0 & 3 & 2 & & & 0 & 0 & 1 & & & 0 & \\
\hline Handianus limbifer & 0 & 0 & 0 & 1 & 1 & 0 & 0 & 0 & 0 & 1 & 2 & 0 & 0 & 0 & 1 & 0 & 0 & 0 & 2 & 0 & 0 & 0 & 1 & 0 & & 0 & 1 & 0 & & & & \\
\hline Laburrus impictifrons & 0 & 0 & 0 & 0 & 0 & 2 & 0 & 0 & 0 & 0 & 1 & 1 & 0 & 0 & 0 & 0 & 0 & 0 & 2 & 0 & & & & & & & & & & & & \\
\hline triola & 0 & 1 & 0 & 1 & 1 & 3 & 0 & 0 & 0 & 0 & 1 & 0 & 0 & 0 & 1 & 1 & 1 & 2 & 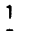 & 0 & 0 & 0 & 3 & & 0 & 0 & 1 & 0 & & 2 & 00 & \\
\hline Matsumurella kogotensis & 0 & 0 & 0 & 1 & 0 & 1 & 0 & 0 & 0 & 0 & 0 & 0 & 0 & 0 & 1 & 0 & 0 & 2 & 2 & 0 & 0 & 0 & 3 & 0 & 0 & 0 & 0 & & & & & \\
\hline Nephotettix cincticeps & 0 & 1 & 0 & 1 & 1 & 3 & 1 & 0 & 0 & 0 & 0 & 0 & 0 & 0 & 0 & 0 & 0 & 0 & 0 & 0 & 0 & 0 & & & & 0 & 0 & & & & & \\
\hline Orientus ishidae & -4 & 1 & 0 & 0 & 0 & 3 & 0 & 0 & 1 & 0 & 0 & 0 & 0 & 1 & 2 & 0 & 0 & 2 & 2 & 0 & 0 & 0 & & & & 0 & & & & & & \\
\hline osus & 0 & 2 & 0 & 0 & 0 & 2 & 1 & 0 & 1 & 0 & 0 & 0 & 0 & 0 & 0 & 0 & 0 & 1 & 1 & 1 & 1 & 3 & 1 & 2 & 1 & 0 & 0 & & & & & \\
\hline Scleroracus jakowleffi & 0 & 1 & 0 & $\underline{0}$ & 1 & $0 / 1$ & 0 & 0 & 0 & 0 & 0 & 0 & 0 & 0 & 0 & 0 & & & & 0 & & & & & & & & & & & & \\
\hline Balclutha incisa & 0 & 0 & 1 & 1 & 0 & 0 & 0 & 0 & 0 & 0 & 2 & 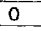 & 0 & 1 & c & 0 & 0 & 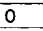 & 1 & 0 & 0 & 0 & 3 & 0 & & 1 & 1 & $\underline{0}$ & & & 0 & \\
\hline Elyman & 0 & 2 & 0 & 0 & 0 & 3 & 0 & 0 & 0 & 0 & 0 & 0 & 0 & 0 & 1 & 1 & 1 & 2 & 2 & 0 & 0 & 0 & 3 & 0 & 0 & 0 & 0 & 0 & & & 0 & \\
\hline Aconurella orientalis & 0 & 0 & 0 & 1 & 1 & 0 & 0 & 0 & $\overline{0}$ & 0 & 0 & 0 & 0 & 0 & 0 & 0 & 0 & 0 & 0 & 1 & 1 & 1 & & & & & & & & & & \\
\hline Doratura gravis & 0 & 0 & 0 & 0 & 1 & 0 & 1 & 0 & 0 & 0 & 2 & 0 & 0 & 0 & & & & & & & & & & & & & & & & & & \\
\hline ¿calus concentralis & 0 & 2 & 0 & 0 & 0 & $\frac{1}{2}$ & 1 & 0 & 0 & 0 & 0 & 0 & 0 & 0 & 0 & 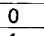 & 0 & 1 & 1 & 1 & 0 & 0 & 2 & 0 & 0 & 0 & & & & & $0 \quad 0$ & \\
\hline Macrosteles strifro & 1 & 3 & 1 & 1 & 1 & 1 & 0 & 1 & 0 & 0 & 1 & 0 & 0 & 1 & 0 & i & 0 & 1 & 1 & 0 & 0 & 0 & & 0 & 0 & & & & & & $\overline{0}$ & \\
\hline Yamatotettix flavovittatus. & -1 & 2 & 0 & 0 & 0 & 0 & 0 & 0 & 0 & 0 & 0 & $\underline{0}$ & 0 & 1 & 0 & 1 & 0 & 0 & & 1 & & 3 & & & & & & & & & 0 & \\
\hline Hishimonus sellatus & 0 & 2 & 0 & 0 & 0 & 2 & 0 & 0 & 0 & 0 & 1 & 1 & 0 & 1 & 0 & 1 & 0 & 0 & 2 & 0 & 0 & 0 & & 0 & 0 & & & & & & 0 & \\
\hline Diplocolenus evansii & 0 & 0 & 0 & 1 & 0 & 2 & 0 & 0 & 列 & 1 & $\overline{2}$ & 2 & 1 & 0 & 0 & ${ }^{2}$ & $\overline{0}$ & 0 & 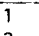 & 1 & 1 & 2 & & 1 & & 0 & 0 & & & & 0 & \\
\hline Jassargus repletus & 0 & 0 & 0 & 1 & 0 & 3 & 1 & 0 & 0 & 1 & 2 & 2 & 1 & 0 & 0 & 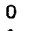 & 0 & & 2 & 0 & 0 & 2 & & & & & & & & & & \\
\hline Metalimnus marmoratus & 0 & 0 & 0 & 1 & 1 & 2 & & & 0 & 1 & 1 & & & 0 & 0 & 1 & & & & & & & & & & & & & & & & \\
\hline Paralaevicephalus nigrifemoratu & 0 & 1 & 0 & 0 & 0 & $1 / 2$ & 0 & 0 & 0 & 1 & 2 & 2 & 0 & 0 & 0 & 0 & 0 & 2 & 2 & 0 & 0 & 1 & & 2 & 0 & 0 & 0 & 0 & & & & \\
\hline Paralimnus tamagawanus & 0 & 2 & 0 & 1 & 0 & 2 & 1 & 0 & 0 & 0 & 0 & 0 & 0 & 0 & 0 & 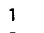 & 1 & ? & & 0 & 0 & 1 & & 2 & & & & & & & 0 & \\
\hline Psammotettix striatus & 0 & 0 & 0 & 0 & 0 & 1 & 1 & 0 & 0 & 1 & 2 & 1 & 0 & 0 & 0 & 0 & 0 & 2 & & 1 & & 3 & & & 0 & & & & & & 0 & \\
\hline Sorhoanus tritici & 0 & 1 & 0 & 0 & 0 & 2 & 1 & 0 & 0 & 0 & 0 & 0 & 0 & 0 & 0 & 0 & & & & & & & & & & & & & & & & \\
\hline Phlogotettix cyclop & 0 & 0 & 0 & 0 & 0 & 1 & 0 & $\overline{0}$ & 0 & 0 & 0 & 0 & 0 & 0 & 0 & 1 & 1 & 1 & 2 & 0 & 0 & 0 & 1 & 0 & $\underline{0}$ & $\underline{0}$ & 0 & 0 & & & 0 & \\
\hline Scaphoideus albovittatus & 0 & 0 & 0 & 0 & 0 & 1 & $\cdot$ & 0 & 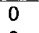 & 5 & 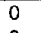 & $=$ & 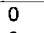 & 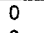 & 5 & 0 & 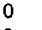 & 0 & & 0 & 0 & 0 & & 0 & & & & & 0 & & 0 & \\
\hline Scaphoideus fest & 0 & 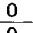 & $\underline{0}$ & 0 & 0 & 1 & 1 & 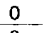 & 0 & 0 & 0 & 2 & 0 & 0 & 0 & 0 & 0 & $\underline{0}$ & & & & $\underline{0}$ & & & & & & & & & & \\
\hline Japananus hyalinus & 0 & 0 & 0 & 1 & 0 & 3 & 1 & $\underline{0}$ & 0 & 0 & 1 & $=$ & 0 & 1 & 2 & 0 & 0 & & & & 2 & & 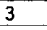 & & & & & 0 & & & 0 & \\
\hline Doratulina grandis & 0 & 0 & 0 & 0 & 2 & 3 & 1 & $\overline{0}$ & 0 & 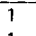 & 1 & 2 & 0 & 0 & 0 & 0 & 0 & 1 & & 1 & $=$ & 0 & 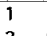 & & & & & 0 & 0 & & 0 & \\
\hline Paivanana indra. & 0 & 0 & 0 & 0 & 1 & 3 & $\frac{1}{n}$ & 0 & 0 & 1 & 1 & 2 & 0 & 0 & 0 & 0 & 0 & 1 & 1 & 1 & 2 & 0 & 2 & 0 & 0 & 0 & $\underline{0}$ & 0 & 0 & & 0 & \\
\hline Amimenus mojiens & 0 & 0 & 0 & 0 & 0 & 3 & 0 & 0 & 0 & 0 & 0 & $\underline{0}$ & 0 & 0 & 1 & 0 & 0 & & & & & & & & & & & & & & & \\
\hline Xestocephalus iguchii & 0 & 1 & 0 & 0 & 0 & 1 & 1 & 1 & 1 & Th & 0 & $\overline{0}$ & 0 & 0 & 1 & - & 0 & & & & & 0 & & 0 & 0 & 0 & 0 & $\underline{0}$ & & & 0 & \\
\hline racomorphus mundus & 0 & 2 & 0 & 0 & 0 & $\leq$ & 1 & 0 & 1 & 0 & 0 & 0 & 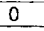 & 1 & 2 & $I$ & 0 & $\leq$ & & $\underline{0}$ & 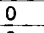 & & 2 & 0 & 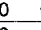 & 0 & 0 & 0 & & & 0 & \\
\hline Planap & $\underline{0}$ & 1 & $\frac{0}{n}$ & 0 & 2 & 0 & $\frac{1}{3}$ & 0 & 1 & 0 & 0 & 0 & 0 & 0 & $\leq$ & $\overline{0}$ & 0 & 2 & I & 0 & 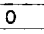 & 0 & & 0 & $\underline{0}$ & 0 & 0 & 0 & $0 \quad 1$ & & 5 & \\
\hline grifemoratus & 0 & 0 & 0 & 1 & $\underline{0}$ & 2 & 0 & & 0 & 0 & 2 & 0 & & & 2 & 1 & 0 & & & & & & & 0 & & & 0 & & & & & \\
\hline Parabo & 0 & 0 & 0 & var & 0 & 2 & $\overline{0}$ & $\overline{0}$ & $\underline{0}$ & 0 & & & & & 0 & 1 & 0 & & & 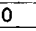 & 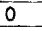 & 0 & & & & & & 0 & 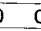 & & 5 & \\
\hline thi & 0 & 0 & & & & & & & 0 & & & 0 & & & & & & & & & & 0 & & & & & & & & & 0 & \\
\hline
\end{tabular}




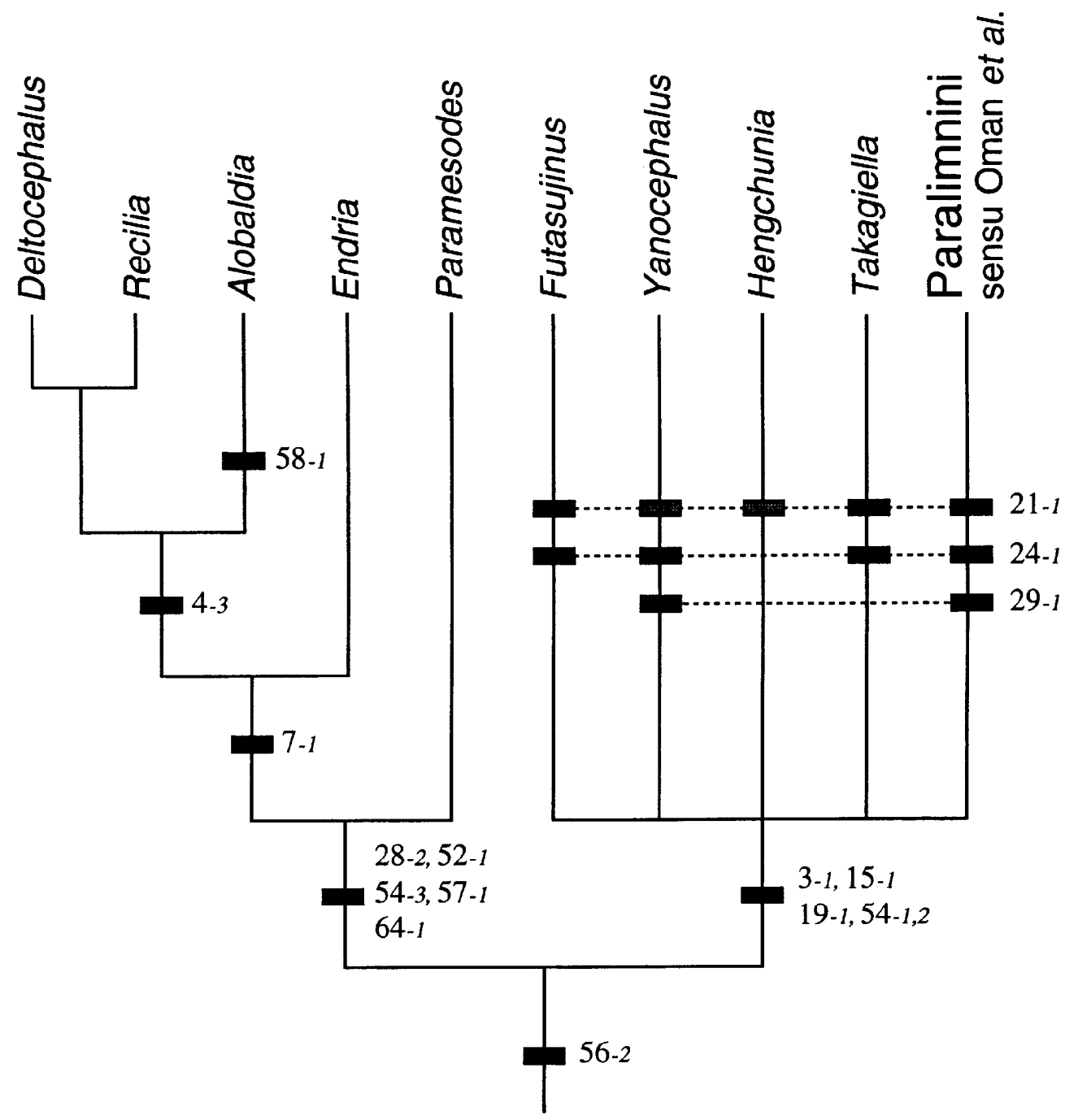

Fig. 1. Phylogenetic relationships for Deltocephalini and Paralimnini reconstructed by the manual method. 


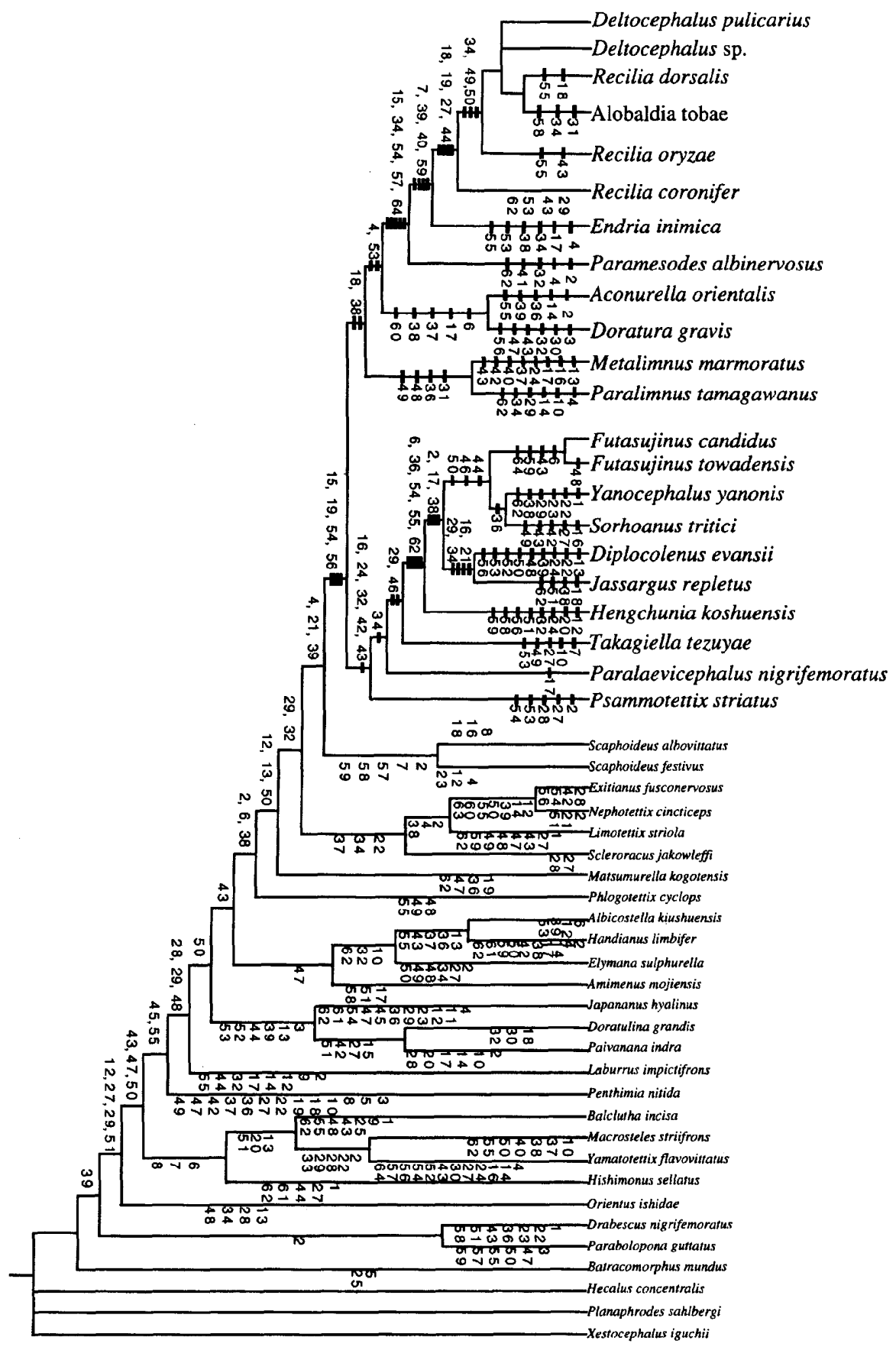

Fig. 2. Fifty percent majority-rule consensus tree of 24 most parsimonious trees using the Fitch chracters. 


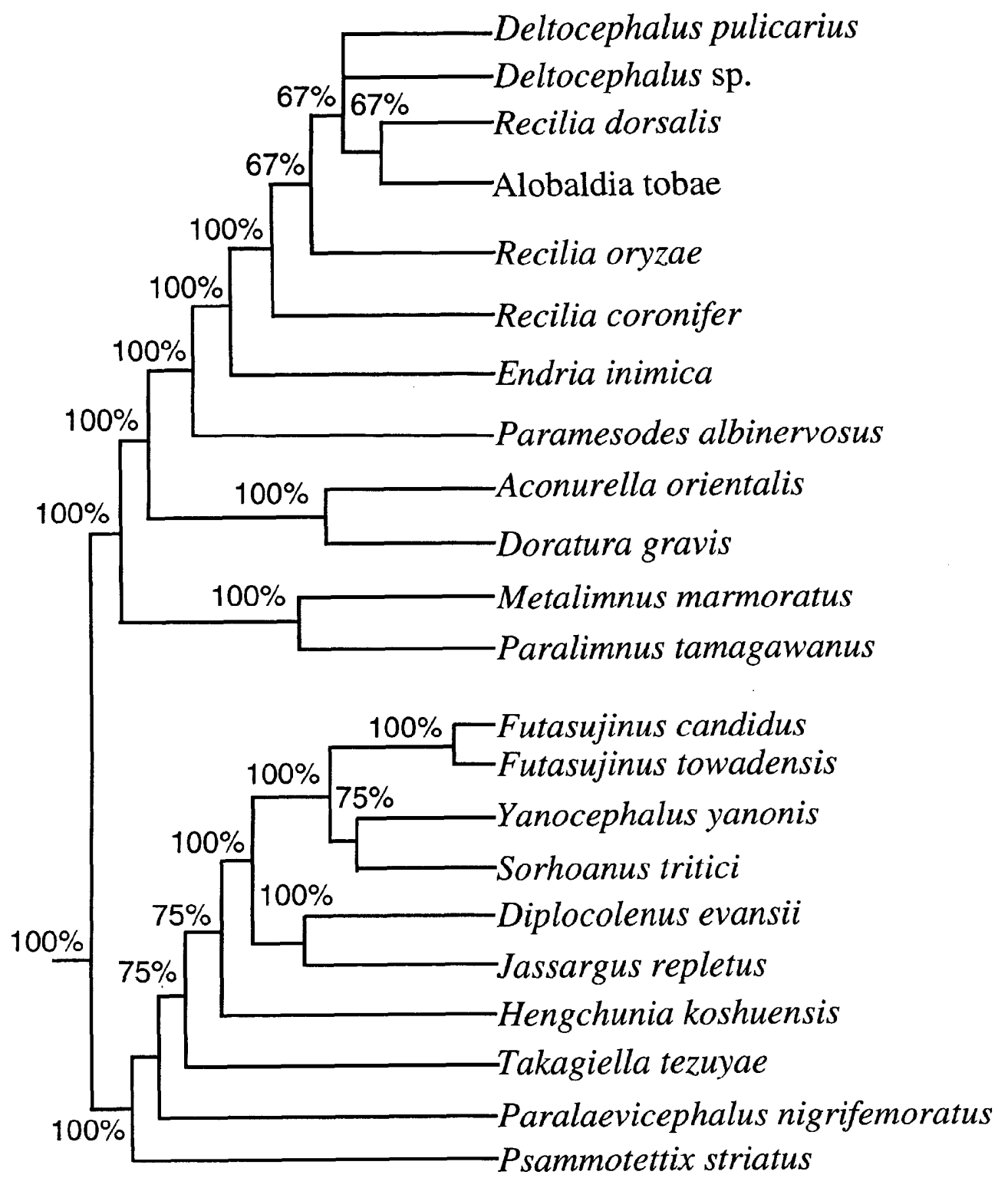

Fig. 3. Consensus frequency between the Deltocephalus and its sister clades by the analyses using the Fitch character. 


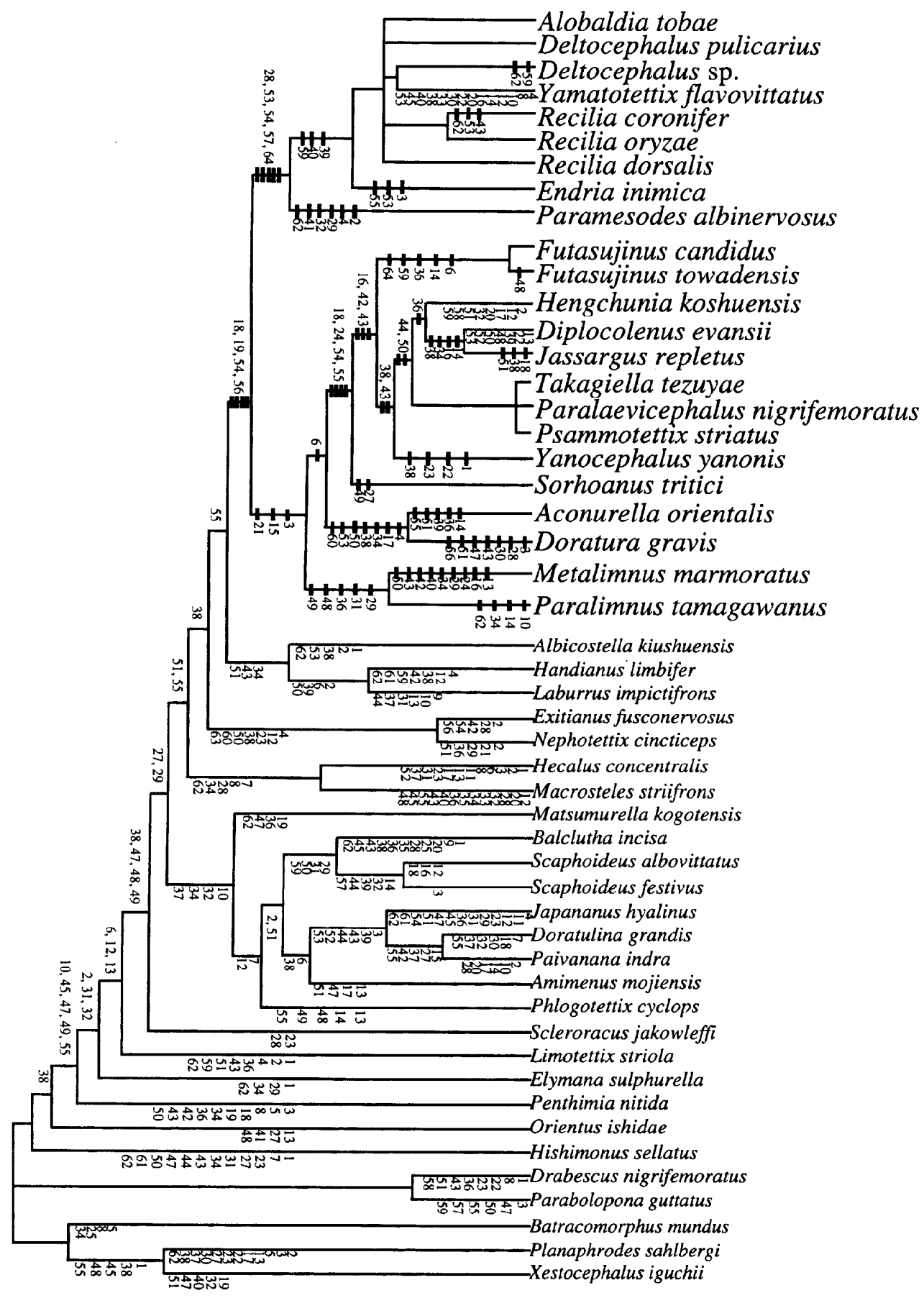

Fig. 4. Fifty percent majority-rule consensus tree of 60 most parsimonious trees using the Wagner chracters. 


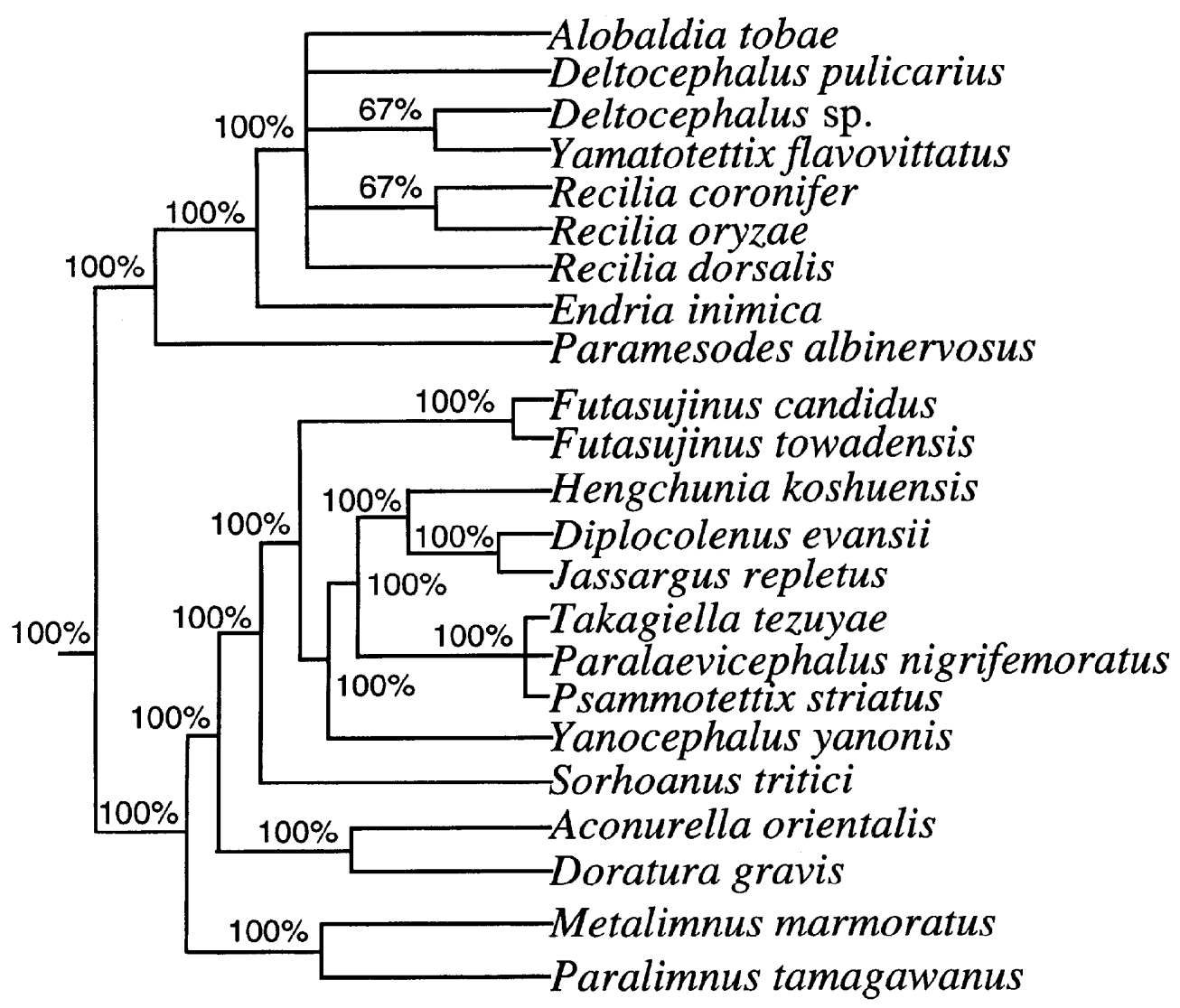

Fig. 5. Consensus frequency between the Deltocephalus and its sister clades by the analyses using the Wagner characters. 


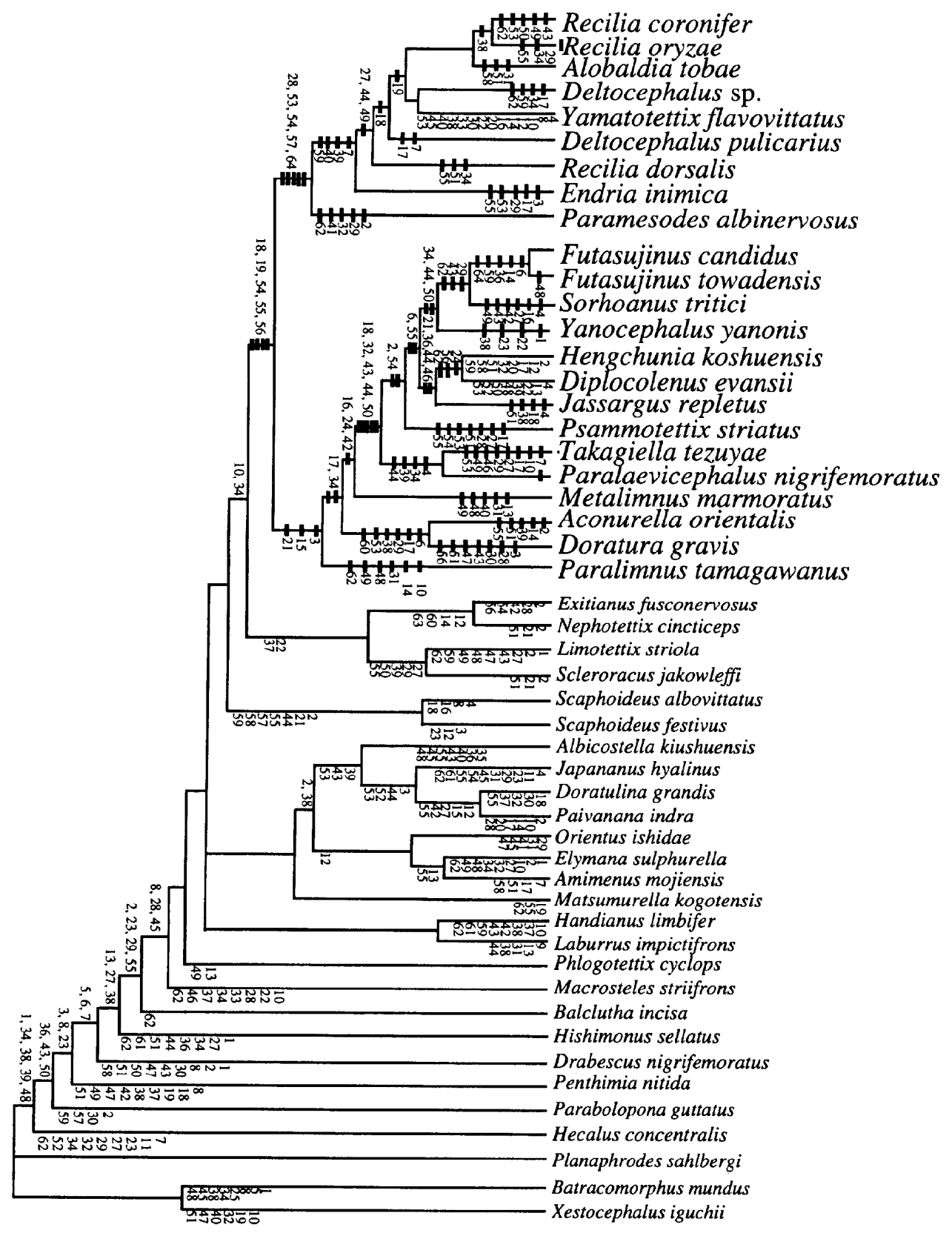

Fig. 6. Fifty percent majority-rule consensus tree of 5 most parsimonious trees using the weighted Wagner chracters. 


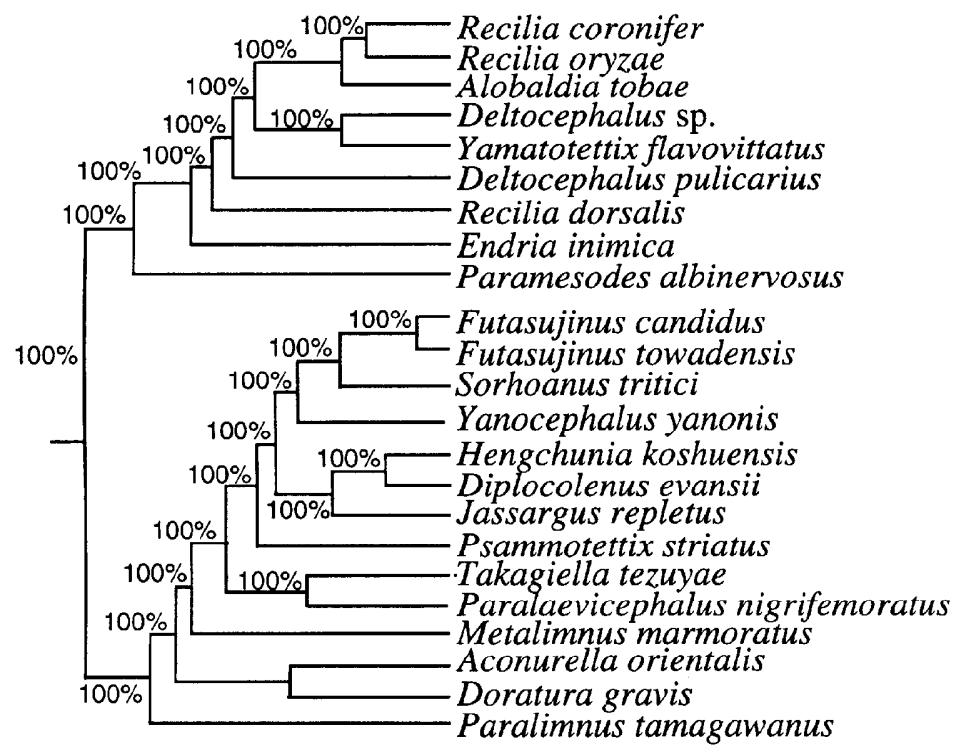

Fig. 7. Consensus frequency between the Deltocephalus and its sister clades by the analyses using the weighted Wagner characters.

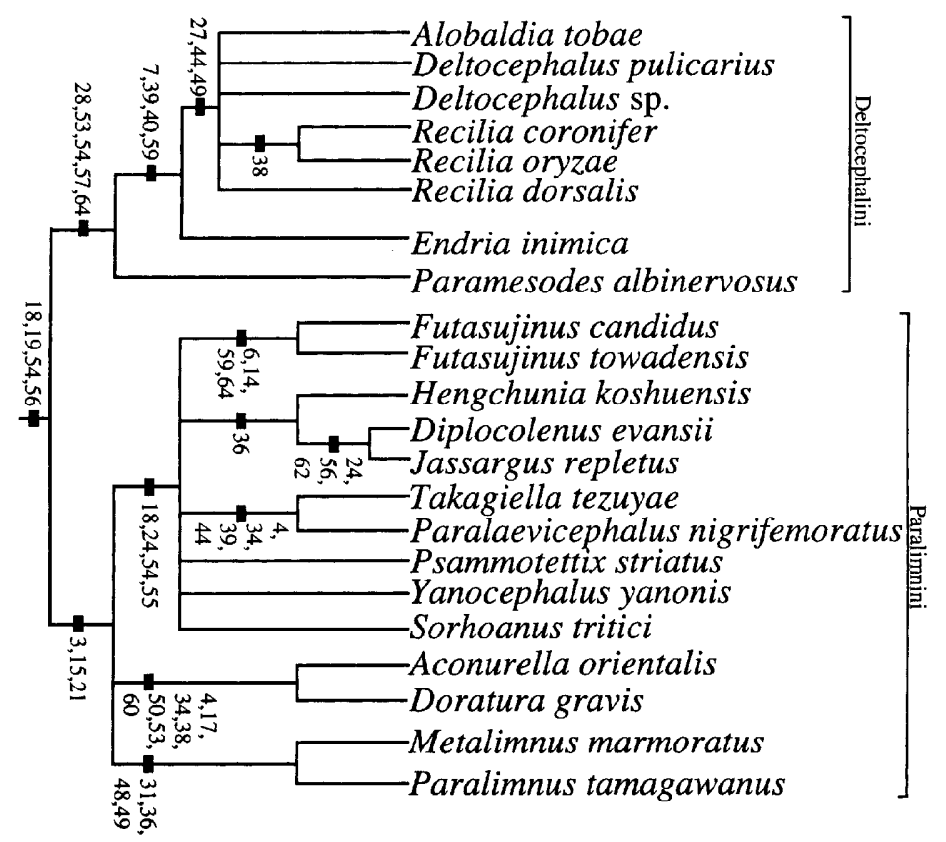

Fig. 8. Phylogenetic tree of the Deltocephalus and its sister clades. 

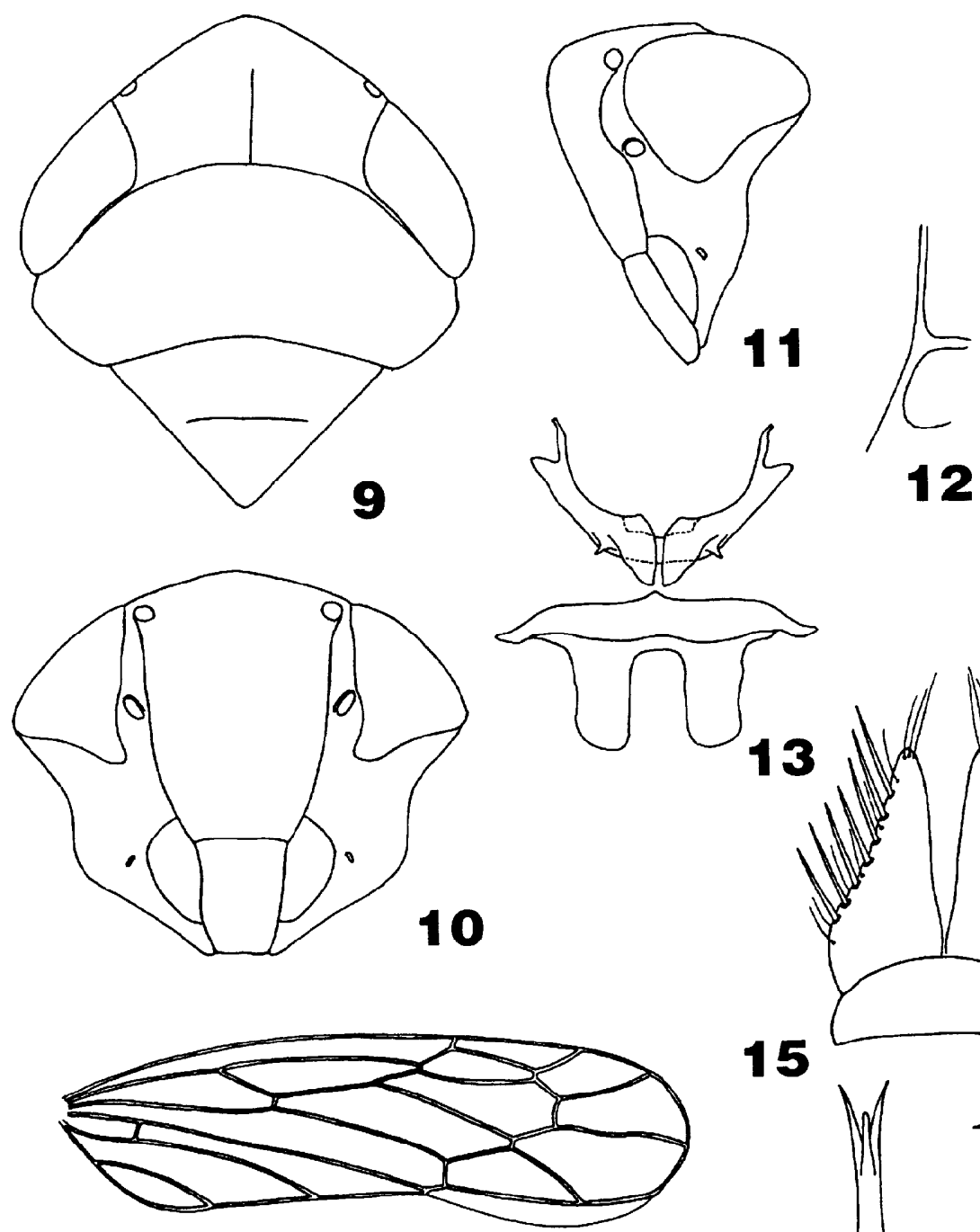

15
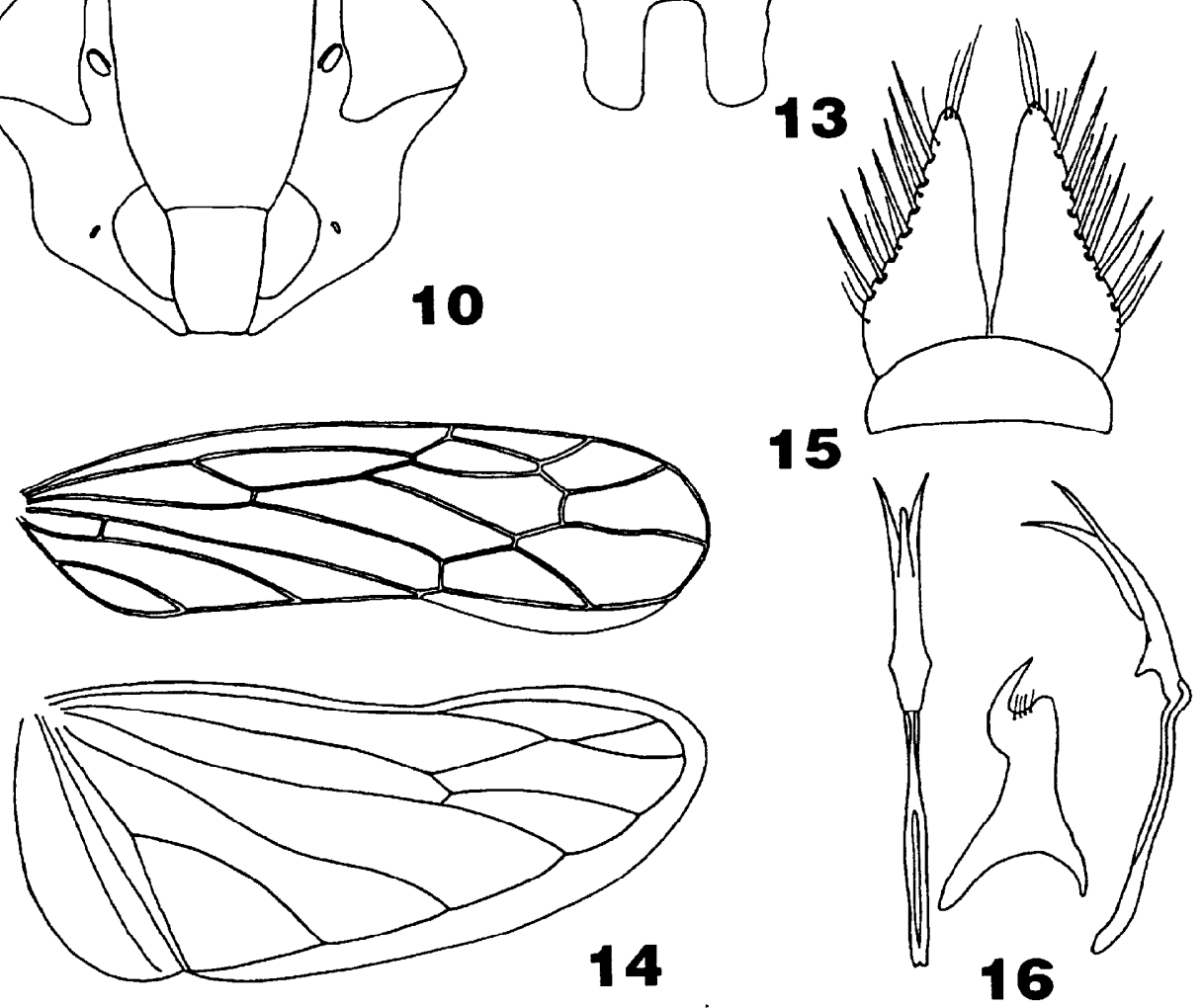

Figs. 9-16. Alobaldia tobae. 9, head, pronotum and scutellum (in dorsal view); 10, head (in anterior view); 11, head (in latral view); 12, tentorium; 13, abdominal apodemes (in dorsal view); 14, fore and hind wings; 15, subgenital valve and plaes; 16 , aedeagus, connective and style (in dorsal and lateral views). 

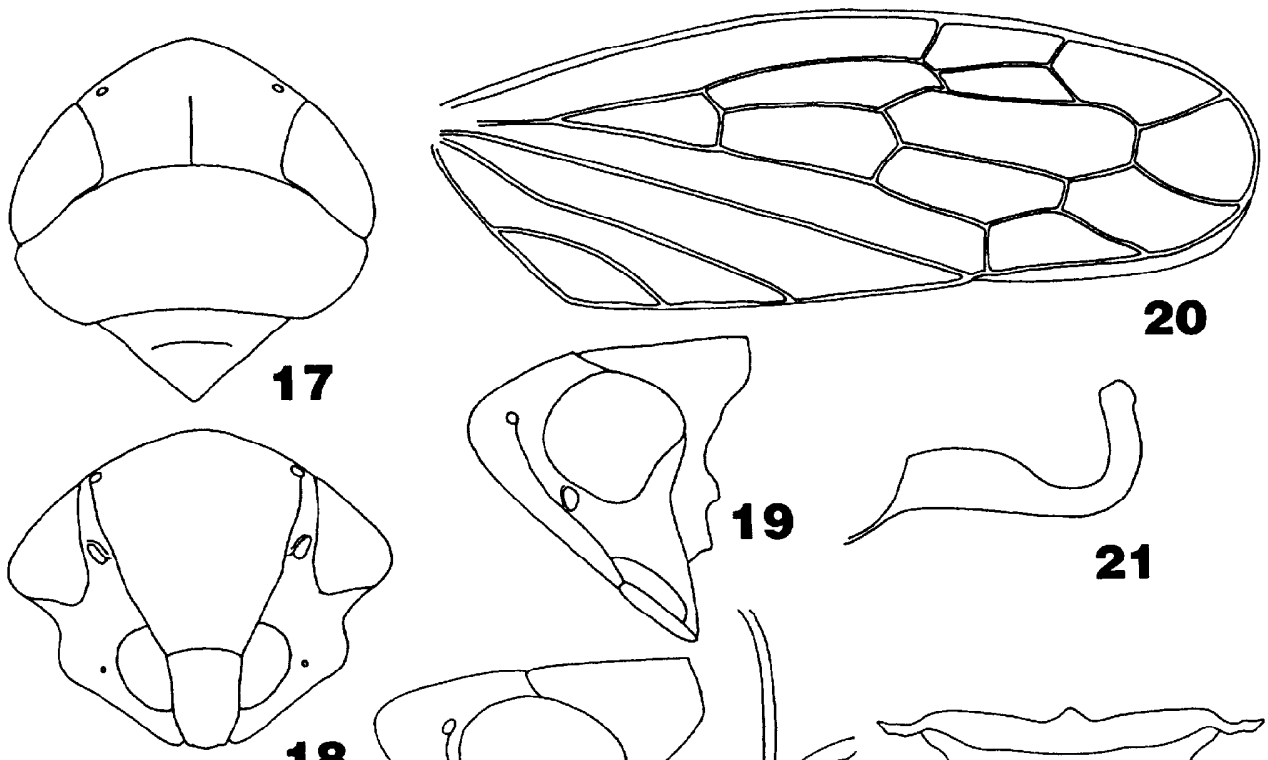

21
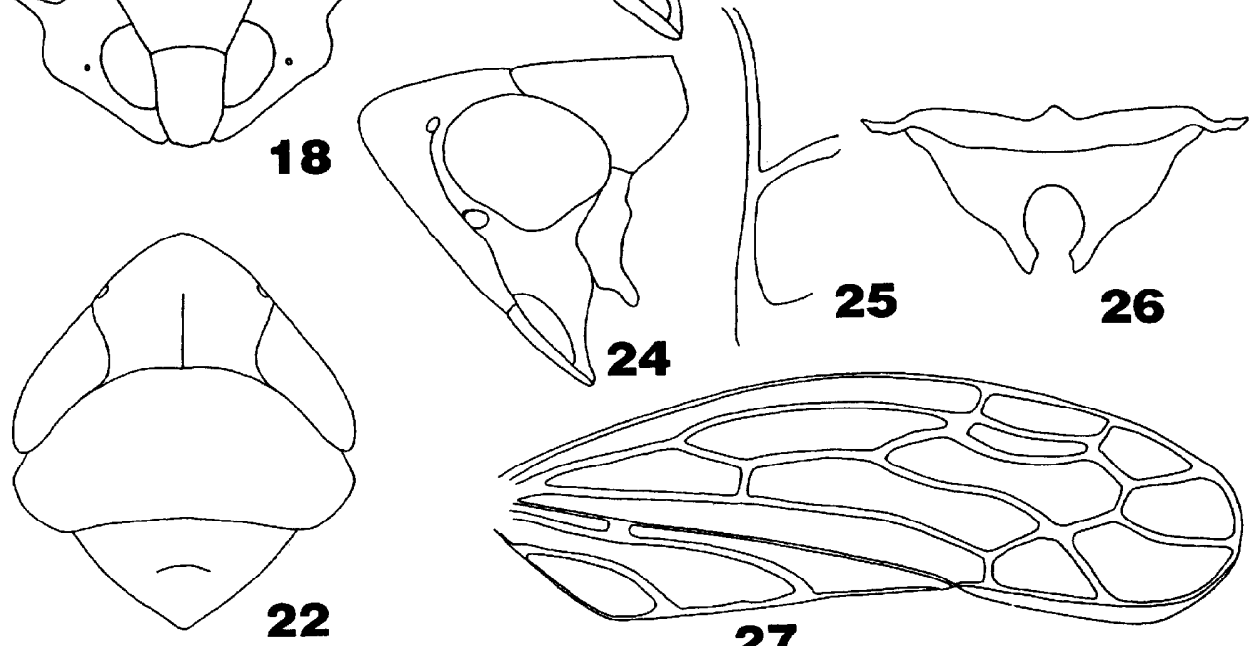

25

26
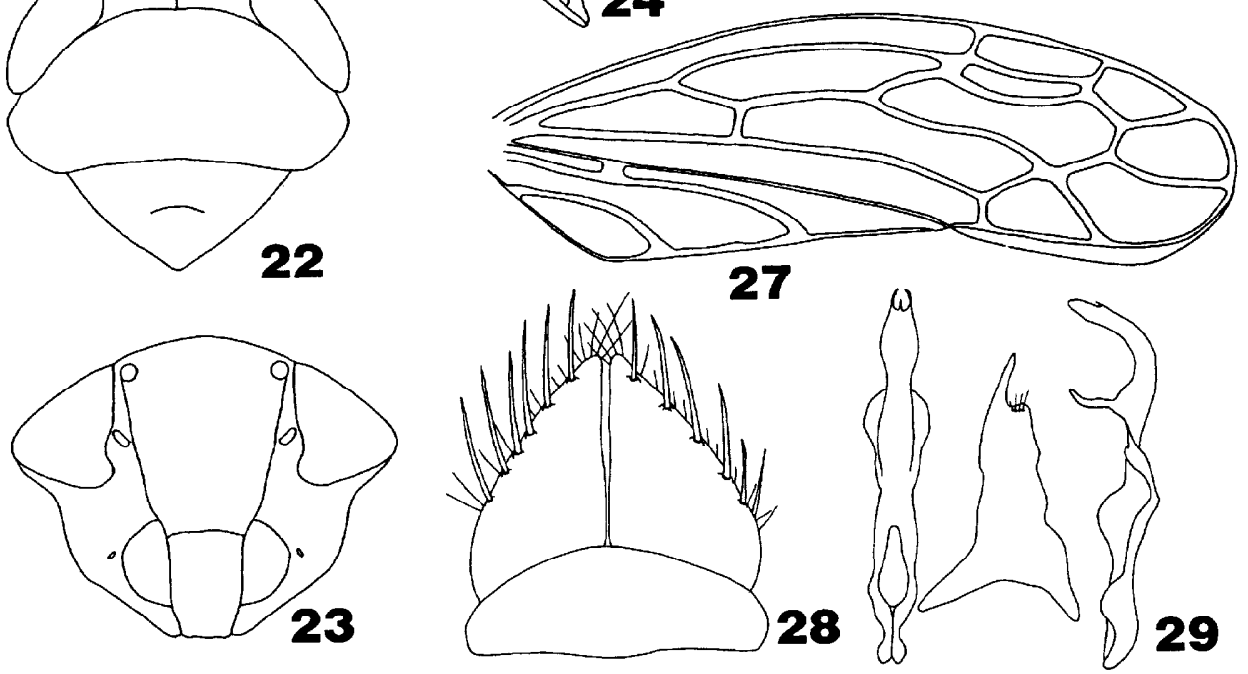

29

Figs. 17-21. Deltocephalus pulicaris. Figs. 22-29. D. sp. 17, 22, head, pronotum and scutellum (in dorsal view); 18, 23, head (in anterior view); 19, 24, head (in latral view); 25, tentorium; 26, abdominal apodemes (in dorsal view); 20, 27, fore wing; 21 , aedeagus (in lateral view); 28, subgenital valve and plaes; 29, aedeagus, connective and style (in dorsal and lateral views). 


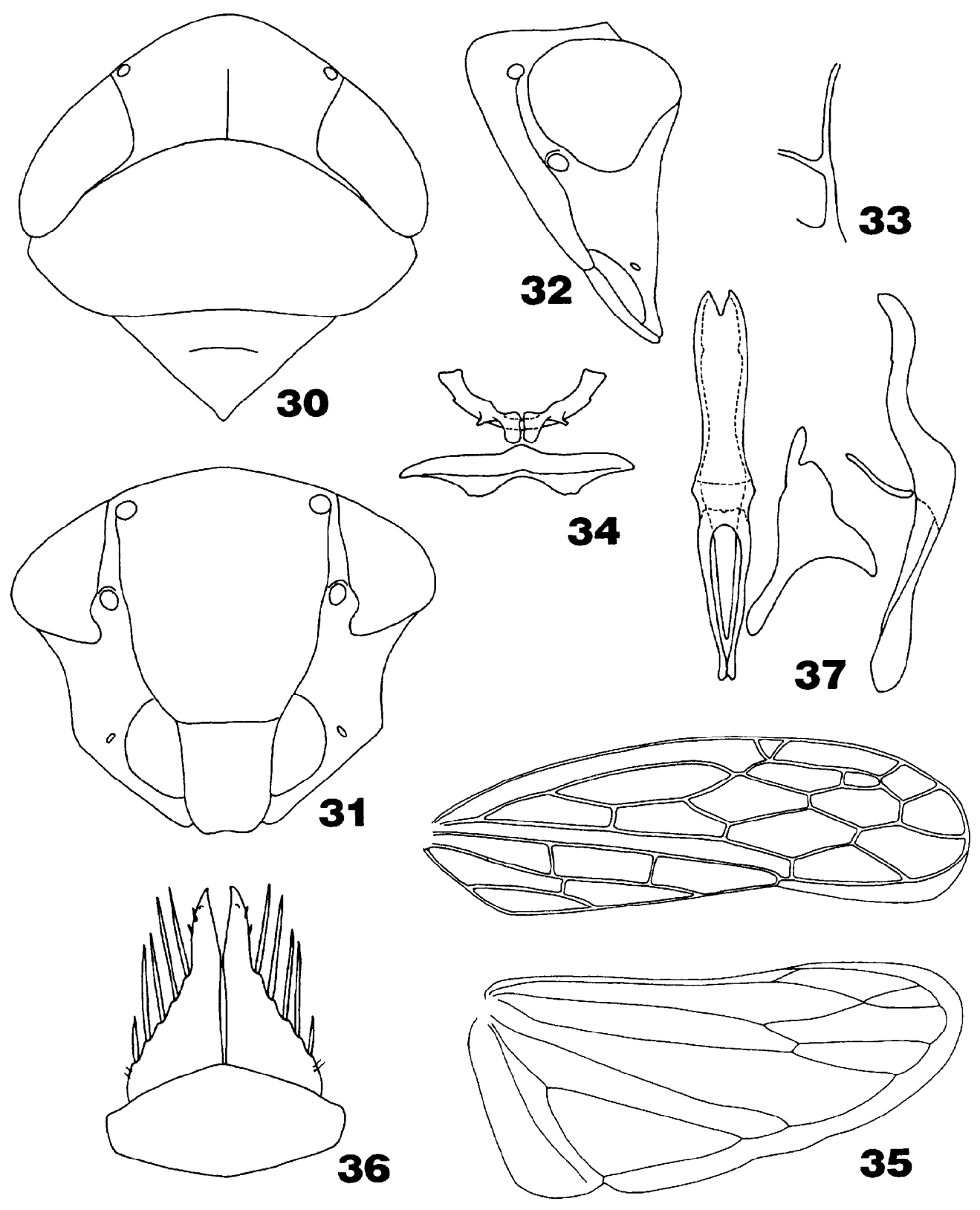

Figs. 30-37. Endria inimica. 30, head, pronotum and scutellum (in dorsal view); 31, head (in anterior view); 32, head (in latral view); 33, tentorium; 34, abdominal apodemes (in dorsal view); 35, fore and hind wings; 36 , subgenital valve and plaes; 37 , aedeagus, connective and style (in dorsal and lateral views). 

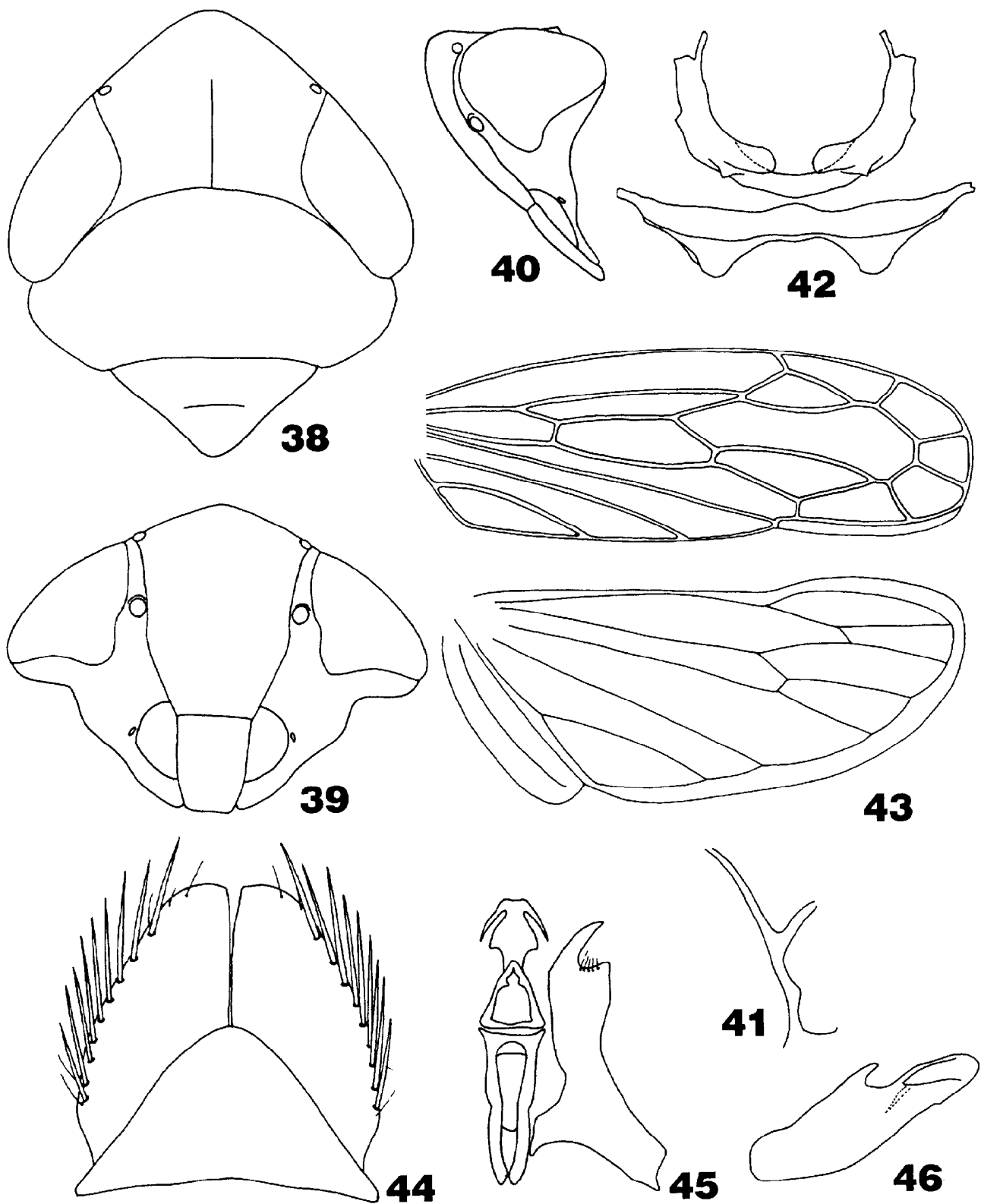

Figs. 38-46. Futasujinus candidus. 38, head, pronotum and scutellum (in dorsal view); 39, head (in anterior view); 40, head (in latral view); 41, tentorium; 42 , abdominal apodemes (in dorsal view); 43, fore and hind wings; 44, subgenital valve and plaes; 45 , aedeagus, connective and style (in dorsal view); 46, aedeagus (in lateral view). 

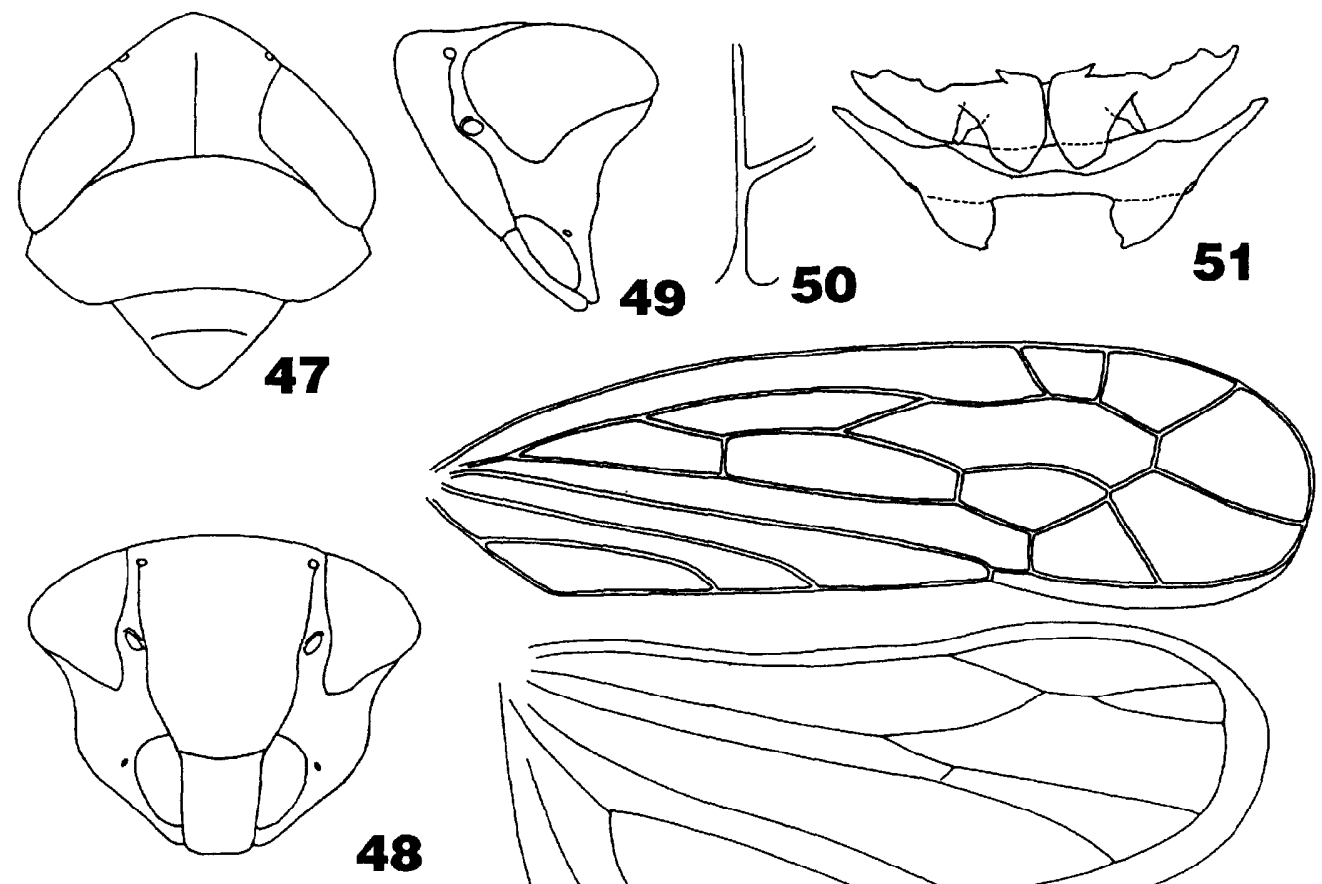

48
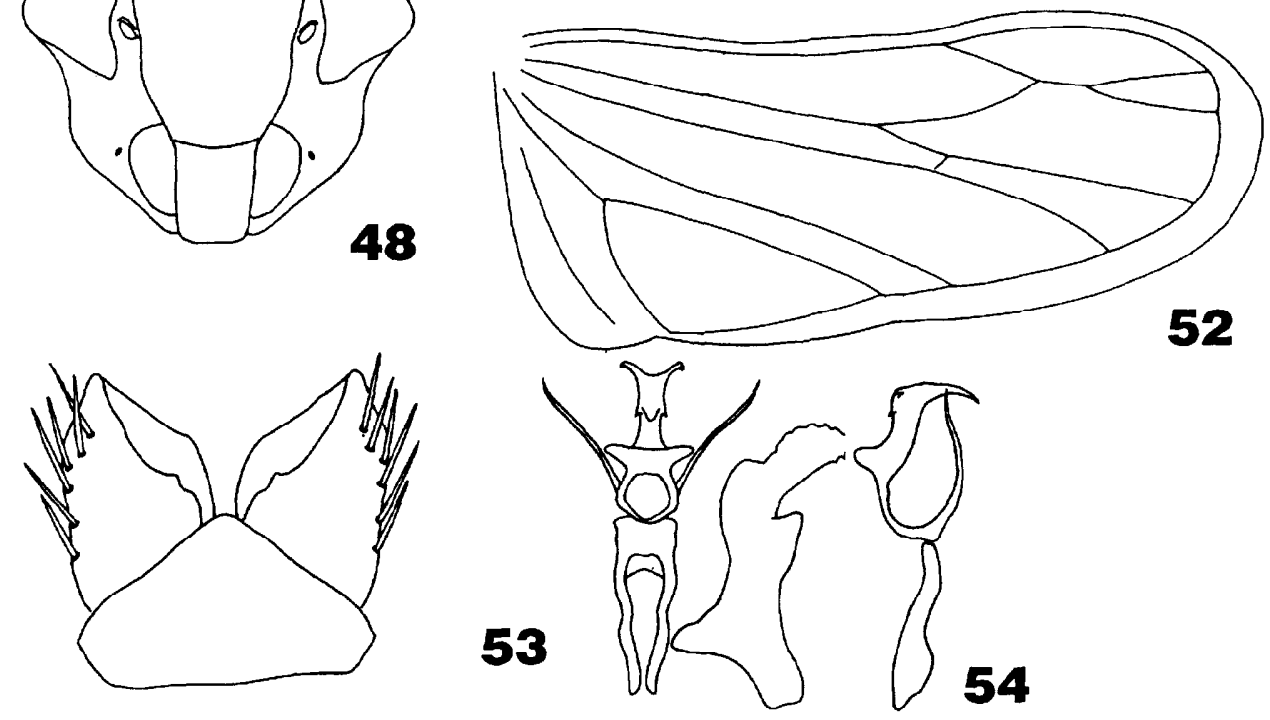

Figs. 47-54. Hengchunia koshuensis. 47, head, pronotum and scutellum (in dorsal view); 48, head (in anterior view); 49, head (in latral view); 50, tentorium; 51, abdominal apodemes (in dorsal view); 52, fore and hind wings; 53, subgenital valve and plaes; 54 , aedeagus, connective and style (in dorsal and lateral views). 

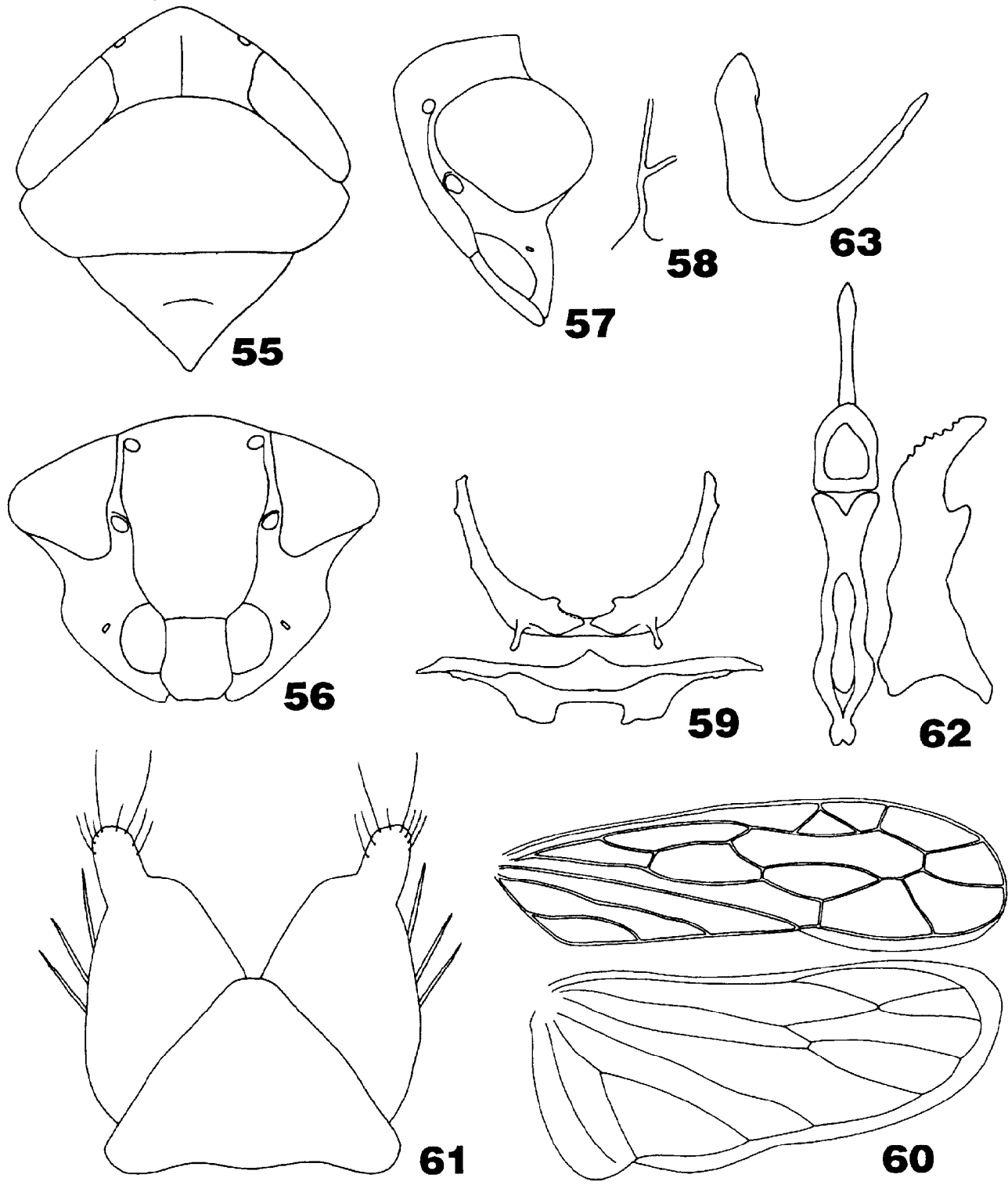

Figs. 55-63. Takagiella tezuyae. 55, head, pronotum and scutellum (in dorsal view); 56 , head (in anterior view); 57, head (in latral view); 58, tentorium; 59, abdominal apodemes (in dorsal view); 60 , fore and hind wings; 61 , subgenital valve and plaes; 62 , aedeagus, connective and style (in dorsal view); 63, aedeagus (in lateral view). 

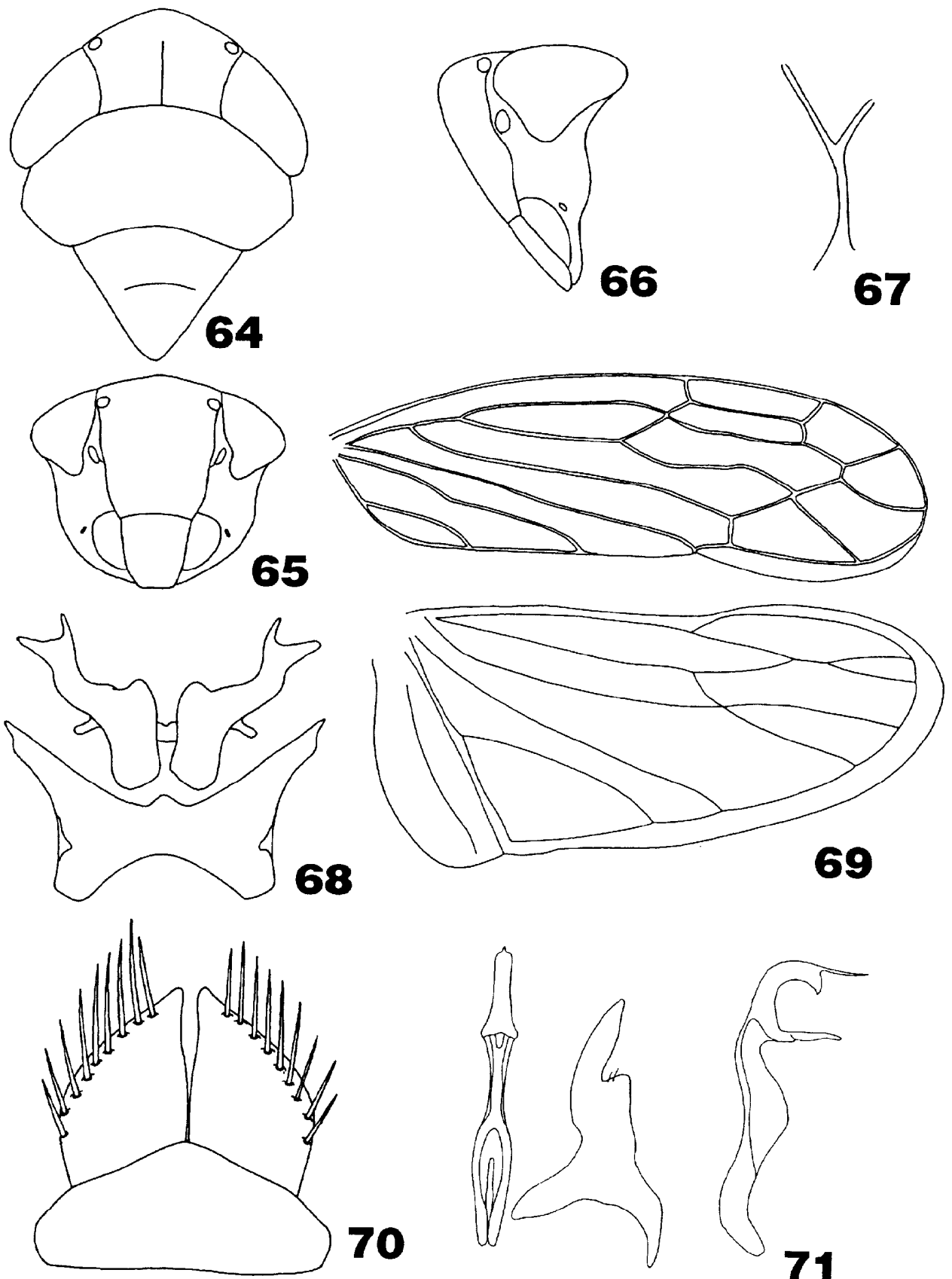

70
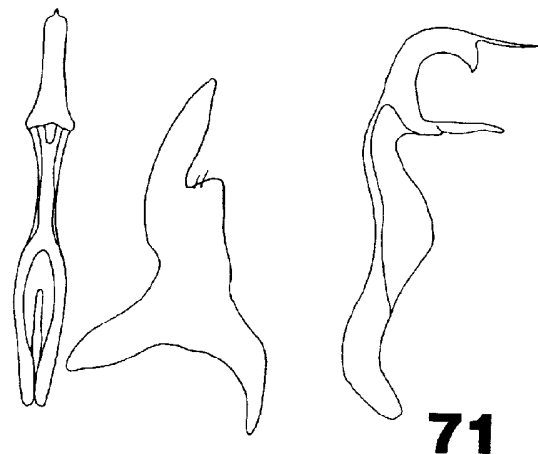

Figs. 64-71. Recilia coronifer. 64, head, pronotum and scutellum (in dorsal view); 65, head (in anterior view); 66, head (in latral view); 67, tentorium; 68, abdominal apodemes (in dorsal view); 69, fore and hind wings; 70, subgenital valve and plaes; 71 , aedeagus, connective and style (in dorsal and lateral views). 

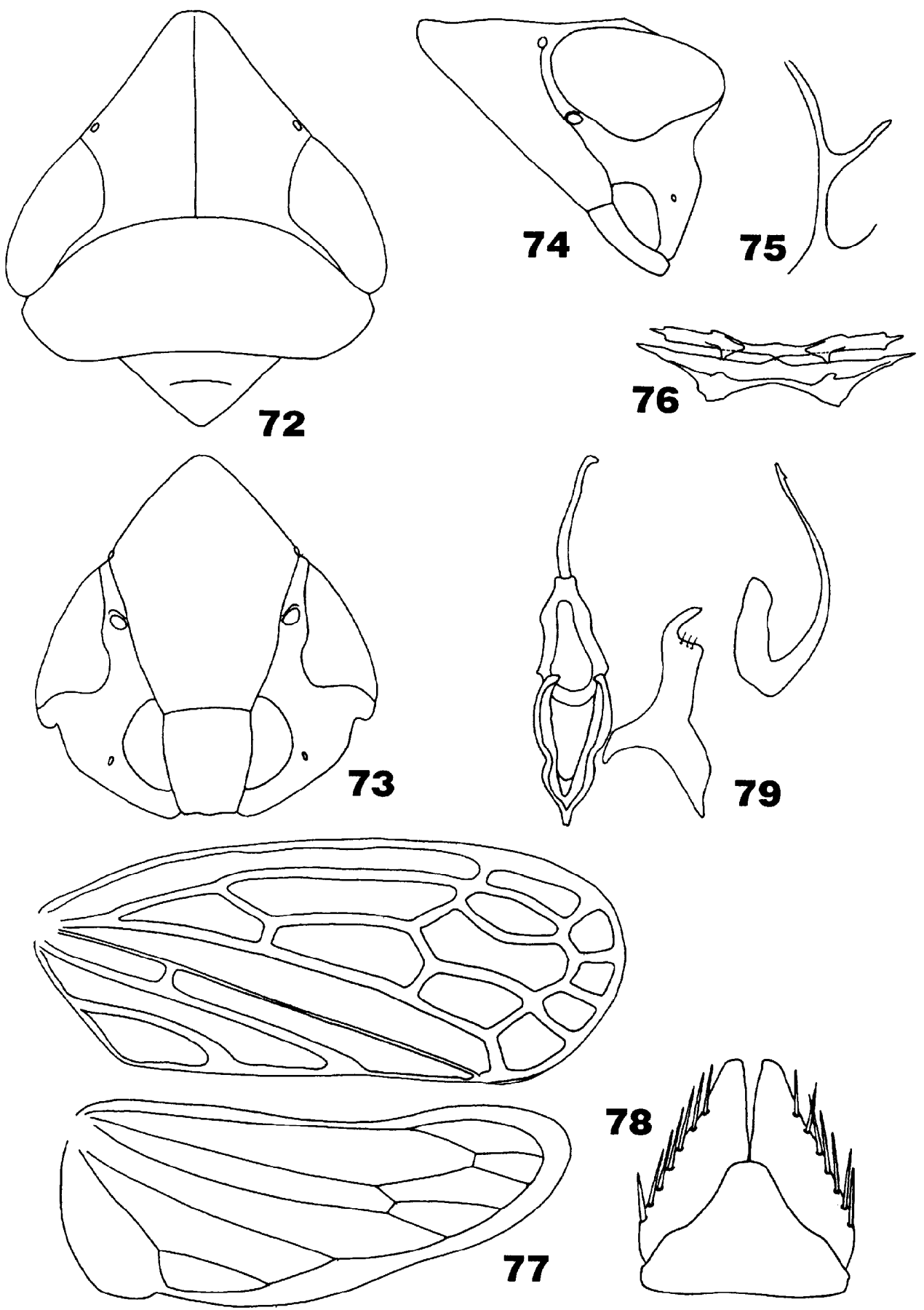


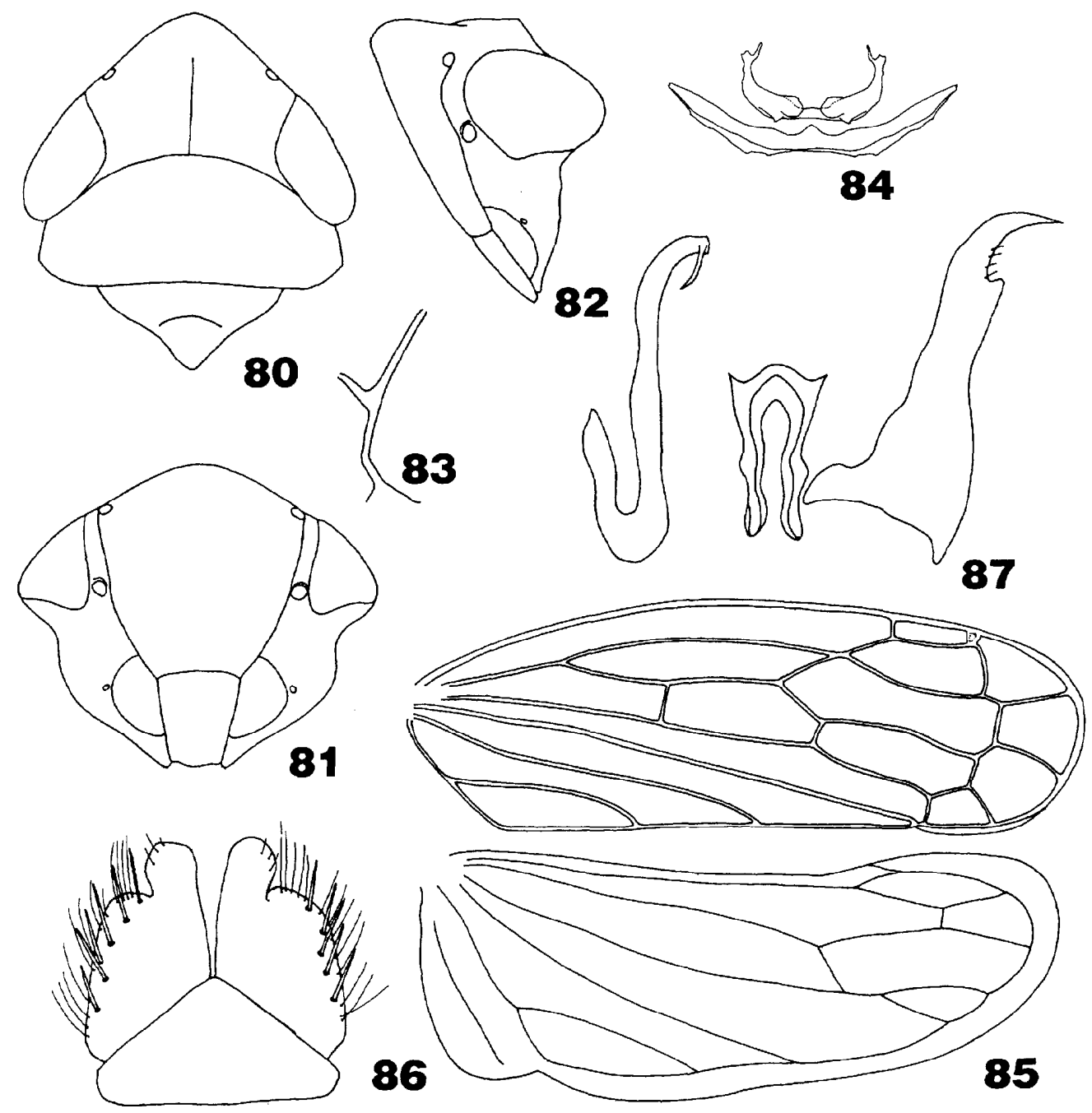

Figs. 80-87. Diplocolenus evansii. 80, head, pronotum and scutellum (in dorsal view); 81, head (in anterior view); 82, head (in latral view); 83, tentorium; 84, abdominal apodemes (in dorsal view); 85 , fore and hind wings; 86 , subgenital valve and plaes; 87 , aedeagus, connective and style (in dorsal and lateral views). 

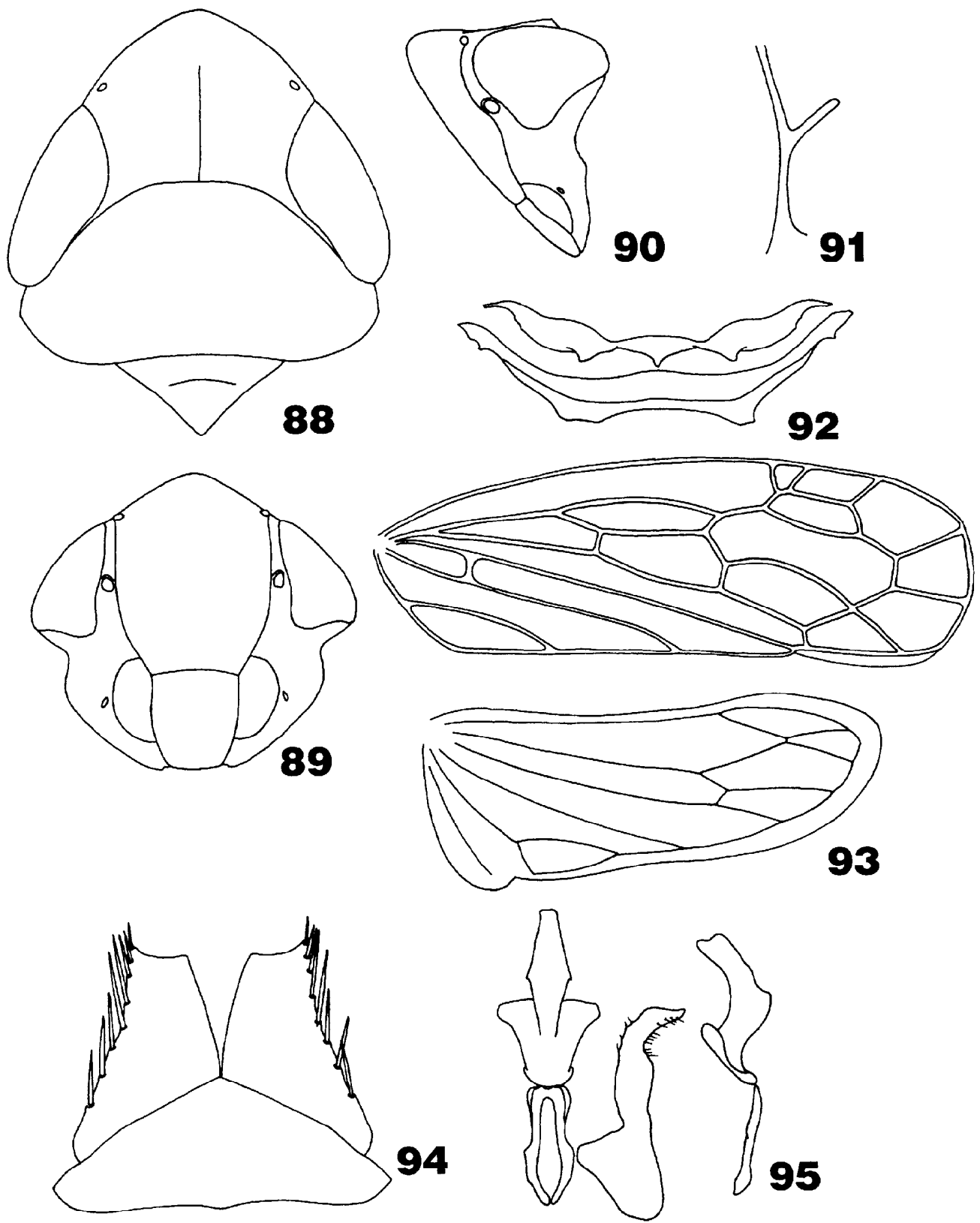

Figs. 88-95. Jassargus repletus. 88, head, pronotum and scutellum (in dorsal view); 89 , head (in anterior view); 90, head (in latral view); 91, tentorium; 92, abdominal apodemes (in dorsal view); 93, fore and hind wings; 94, subgenital valve and plaes; 95 , aedeagus, connective and style (in dorsal and lateral views). 

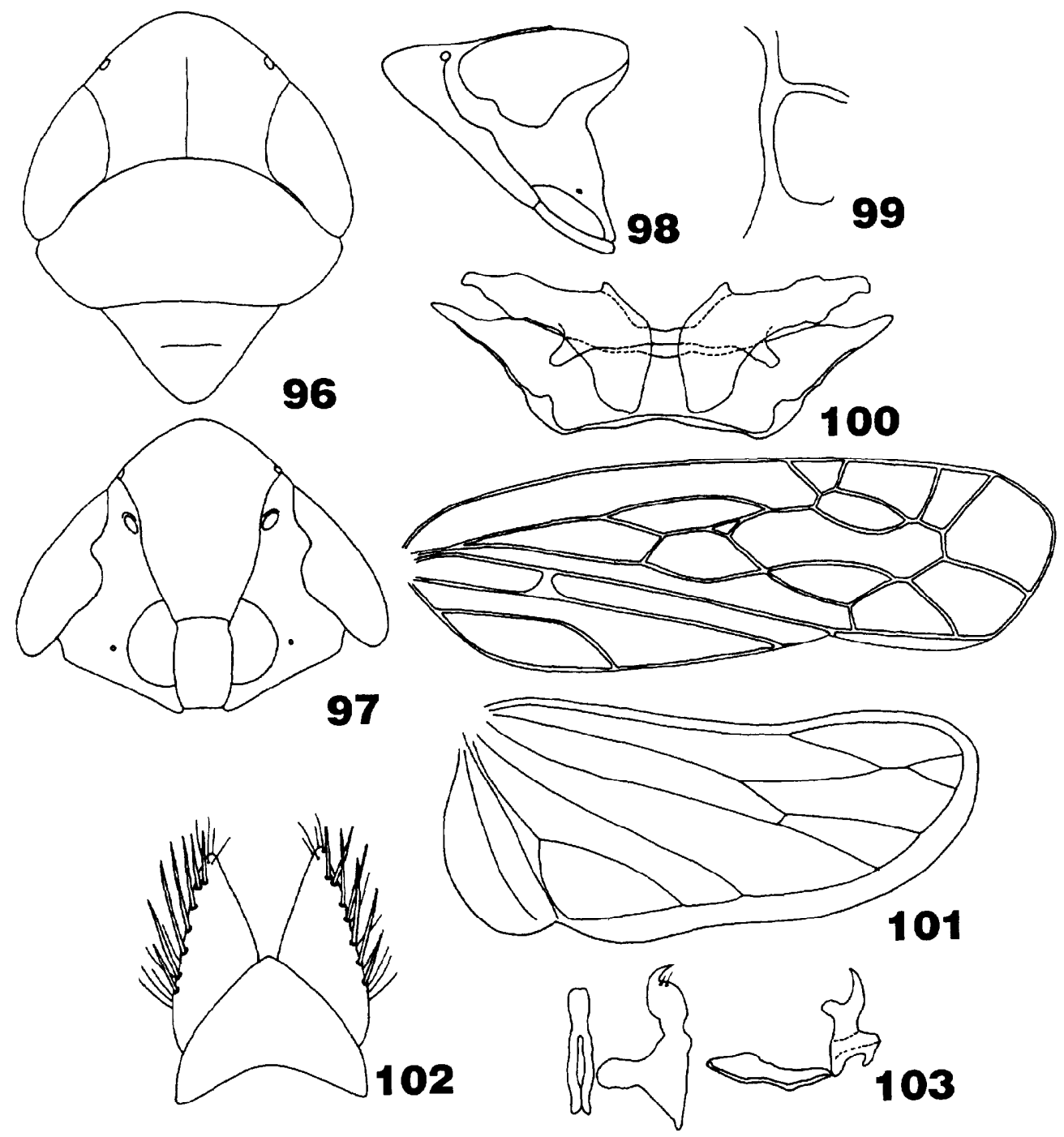

Figs. 96-103. Metalimnus marmoratus. 96, head, pronotum and scutellum (in dorsal view); 97, head (in anterior view); 98, head (in latral view); 99, tentorium; 100, abdominal apodemes (in dorsal view); 101, fore and hind wings; 102, subgenital valve and plates; 103, aedeagus, connective and style (in dorsal and lateral views). 

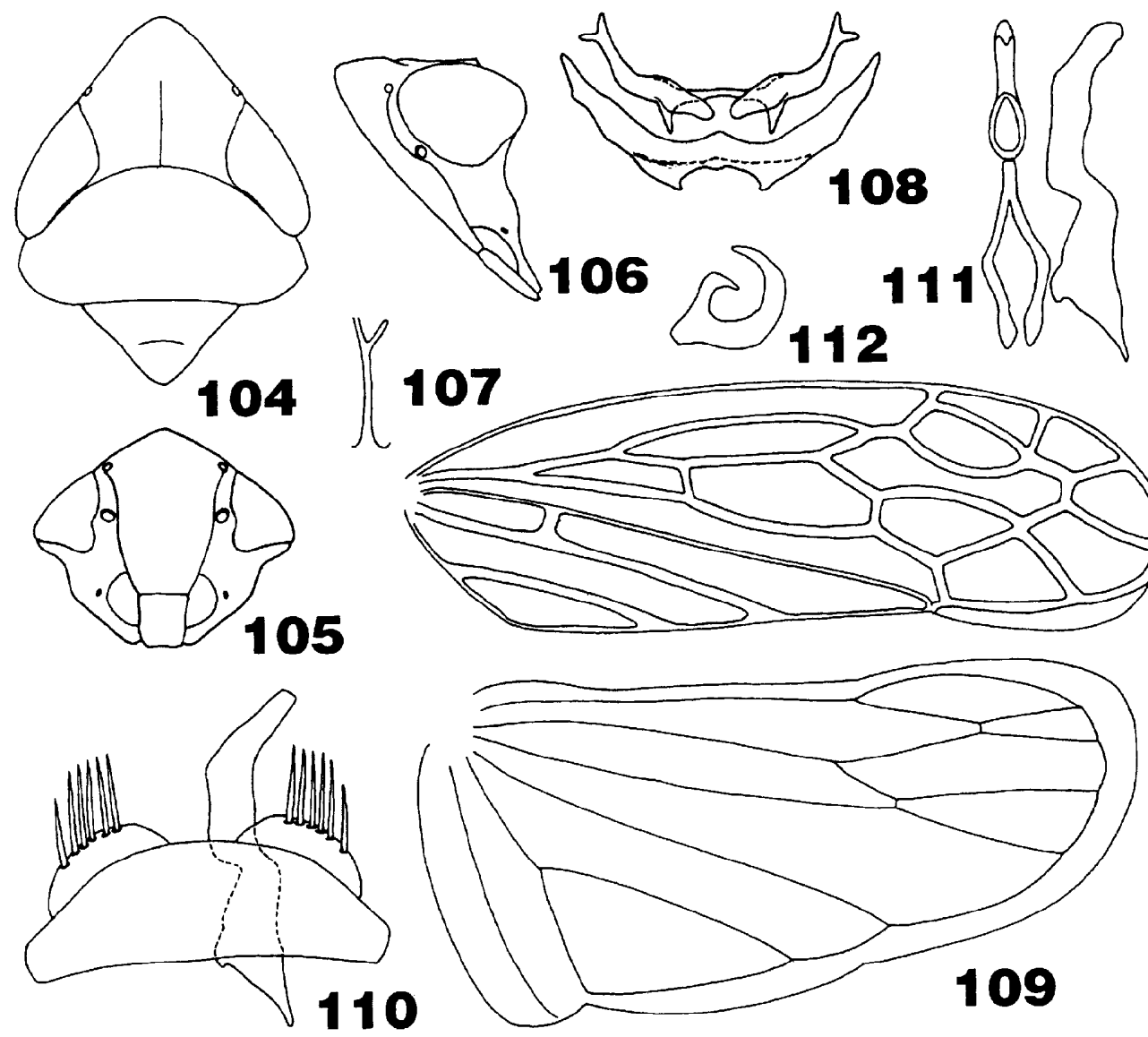

Figs. 104-112. Paralaevicephalus nigrifemoratus. 104, head, pronotum and scutellum (in dorsal view); 105, head (in anterior view); 106, head (in latral view); 107 , tentorium; 108, abdominal apodemes (in dorsal view); 109, fore and hind wings; 110 , subgenital valve and plaes; 111, aedeagus, connective and style (in dorsal views); 112, aedeagus (in lateral view). 

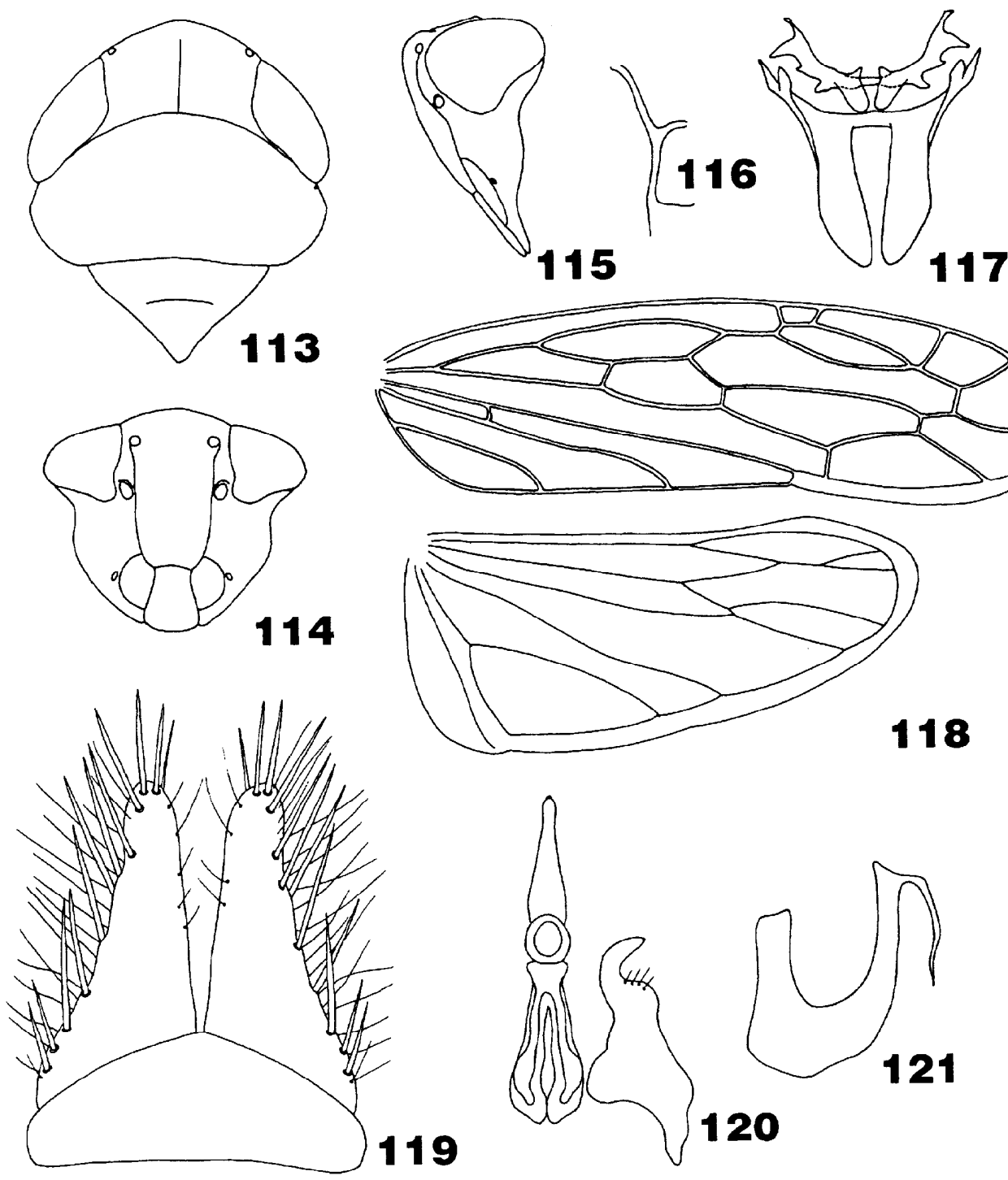

117

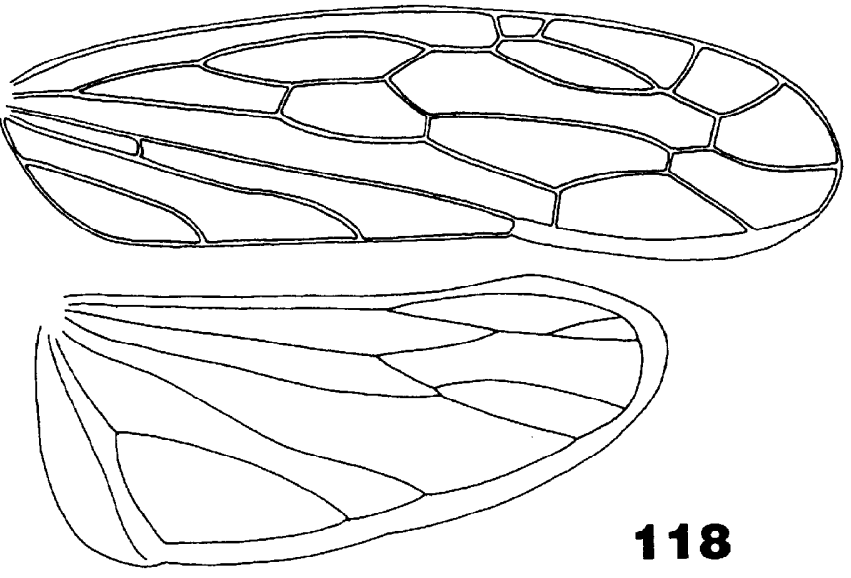

119

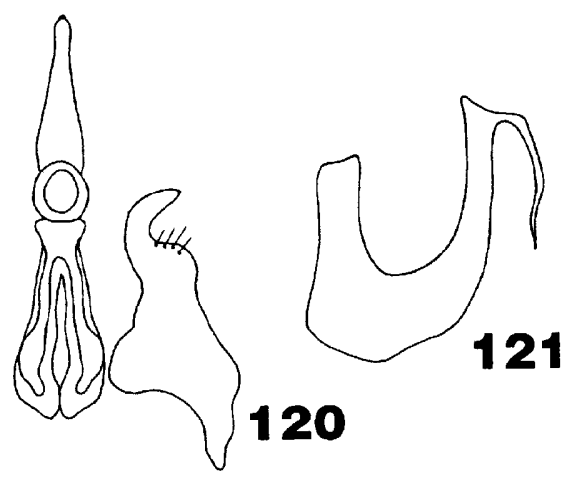

Figs. 113-121. Paralimnus tamagawanus. 113, head, pronotum and scutellum (in dorsal view); 114, head (in anterior view); 115, head (in latral view); 116 , tentorium; 117, abdominal apodemes (in dorsal view); 118, fore and hind wings; 119 , subgenital valve and plaes; 120 , aedeagus, connective and style (in dorsal view); 121, aedeagus (in lateral view). 


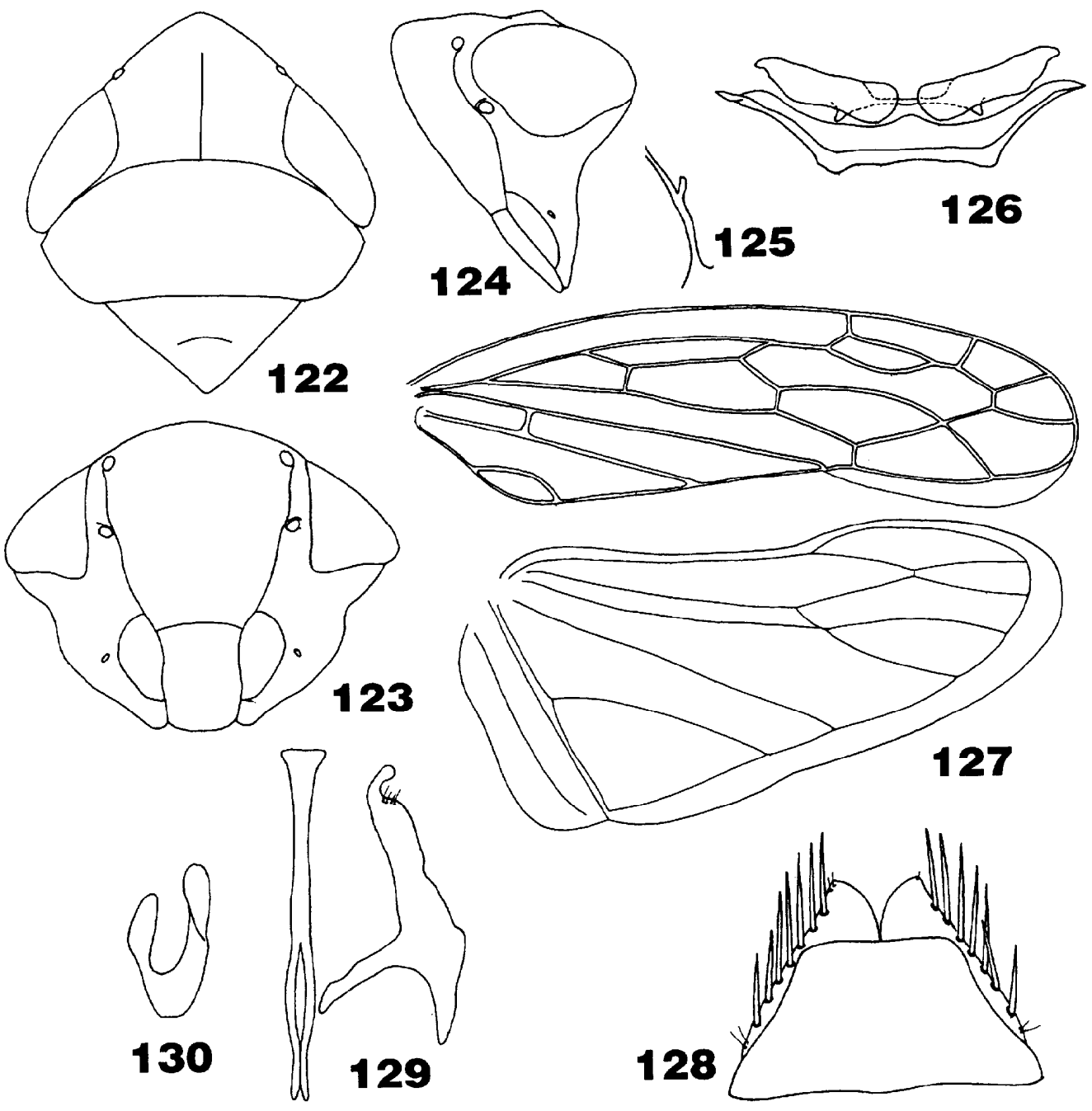

Figs. 122-130. Psammotettix striatus. 122, head, pronotum and scutellum (in dorsal view); 123, head (in anterior view); 124, head (in latral view); 125, tentorium; 126, abdominal apodemes (in dorsal view); 127, fore and hind wings; 128, subgenital valve and plaes; 129, aedeagus, connective and style (in dorsal view); 130 , aedeagus 'in lateral views). 

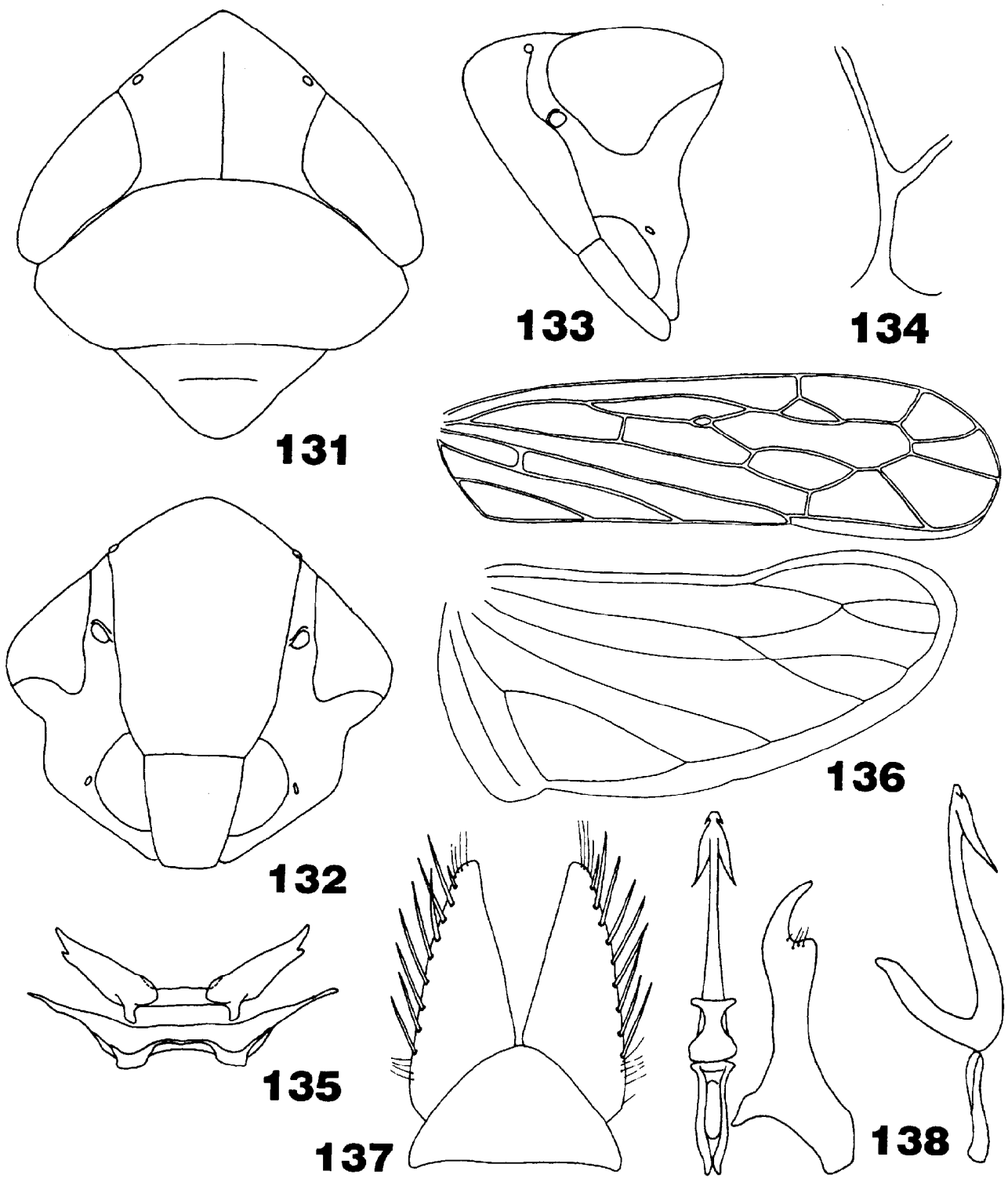

Figs. 131-138. Sorhoanus tritici. 131, head, pronotum and scutellum (in dorsal view); 132, head (in anterior view); 133, head (in latral view); 134, tentorium; 135 , abdominal apodemes (in dorsal view); 136, fore and hind wings; 137, subgenital valve and plaes; 138, aedeagus, connective and style (in dorsal and lateral views). 